\title{
BEYOND BITCOIN: \\ LEVERAGING BLOCKCHAIN TO BENEFIT BUSINESS AND SOCIETY
}

\author{
Marcia Narine Weldon \& Rachel Epstein*
}

"It is] very important. . . to reserve our spot [in the blockchain space] even before we know what the commercial application might be." - Catherine Bessant, Chief Technology Officer, Bank of America, discussing the company's application for dozens of blockechain patents. ${ }^{1}$

\section{TABLE OF CONTENTS}

I.A Brief Introduction to Cryptocurrencies, Blockchain, and Smart Contracts
A. What is Bitcoin?
B. What is Blockchain?
C. What is a Smart Contract?

II.Blockchain Use Cases for Private Enterprise and State Actors
A. Food and Drug Supply
B. Healthcare
C. Banking and Finance
D. Supply Chain and Logistics
E. State Actors

\footnotetext{
* Marcia Narine Weldon teaches at the University of Miami School of Law; consults with businesses of all sizes on compliance, corporate governance, and sustainability; and has served as a Deputy General Counsel, Chief Compliance Officer, and Chief Privacy Officer for a Fortune 500 company that manages other companies' supply chains. Rachel Epstein was first exposed to blockchain while serving as a research assistant for Professor Aaron Wright on his book titled BLOCKCHAIN AND THE LAW: THE RulE OF CODE. She learned more about the impact of this new decentralized technology as in-house counsel at ConsenSys where she also co-authored Not so FastRisks Related to the Use of a "Saft" for Token Sales as part of the Brooklyn Project and wrote an article about tokens and securities laws published in the New York State Bar Law Association Journal. Rachel currently serves on the legal team as corporate counsel at Hedera Hashgraph. We would like to thank the editors of TenN. J. Bus. L., the audience members at the Business Law: Connecting the Threads II Conference at the University of Tennessee College of Law, and the participants of the Lutie A. Lytle Black Women Law Professors Faculty Workshop for their insightful comments on Professor Narine Weldon's early presentations on this topic. Finally, we thank Natalia Jaramillo, Jordan Suarez, and Lauren Miller for their invaluable research assistance.

${ }^{1}$ William Choi \& Pablo Florian, The Race to Patent the Blockchain, Alix PARTNERS 2 (Sept. 2016), https://emarketing.alixpartners.com/rs/emsimages/2016/pubs/FAS/AP_The_ Race_to_Patent_the_Blockchain_Sep_2016.pdf.
} 
1. Land Title Registries

2. E-Government and Citizen Services

3. Identity Management

4. Blockchain and the Sustainable Development Goals

III.Corporate Governance, Compliance, and Enterprise Risk

Management

1. Blockchain and Audit

2. Blockchain and Know Your Customer/Anti-money Laundering Compliance

3. Blockchain and Cybersecurity

4. Blockchain and Corporate Governance

IV.Blockchain and Human Rights Disclosures

A. Voluntary Corporate Social Responsibility Disclosures

1. OECD Guidelines for Multinational Enterprises

2. Global Reporting Initiative

3. U.N. Global Compact

4. ISO 26000:2010

5. U.N. Guiding Principles on Business and Human Rights

6. Sustainability Accounting Standards Board

B. U.S. Regulations on Corporate Social Responsibility Disclosures

1. Dodd-Frank Conflict Minerals Act

2. California Transparency in Supply Chains Act

3. Federal Acquisition Regulations

C. International Regulations on Corporate Social

Responsibility Disclosures

1. EU Non-Financial Disclosure Laws

2. UK Modern Slavery Act of 2015

3. France's Duty of Vigilance Law

4. Commonwealth Modern Slavery Act

5. EU Conflict Minerals Rule

D. Difficulties with Disclosure and How Blockchain Could Help

V.Conclusion 


\section{INTRODUCTION}

Many have called blockchain the most disruptive technology since the advent of the Internet, and others have hailed it as "Internet 2.0." The hyperbole has nothing to do with getting rich from cryptocurrency. If you ate at McDonald's, used dried coconut, chopped romaine lettuce in a salad, dined in a Panera bakery, had Honey Smacks cereal for breakfast, or snacked on Ritz crackers in 2018, you likely experienced a food recall. ${ }^{3}$ Blockchain aims to reduce the traceability time for foods and medicines from weeks to seconds, enabling farmers to avoid financial ruin and consumers to avoid illnesses. ${ }^{4}$ If you have concerns about the integrity of elections after allegations of interference with the 2016 election in the United States, blockchain technology purports to provide a tamper-proof way to vote. ${ }^{5}$ If you have ever tried to send money overseas, you know that it can be an expensive and slow process. Blockchain enthusiasts want to disrupt the $\$ 600$ billion remittance industry by eliminating the need for intermediaries. ${ }^{6}$ Anyone who has tried to access his or her own medical

2 See e.g., Brian Fung, Marc Andreessen: In 20 Years, Well Talk. About Bitcoin Like We Talk About the Internet Today, WASH. POST (May 21, 2014), https://www.washingtonpost.com/ news/the-switch/wp/2014/05/21/marc-andreessen-in-20-years-well-talk-about-

bitcoin-like-we-talk-about-the-internet

today/?noredirect $=$ on\&utm_term $=$. a8ebc1a87abe (quoting Netscape founder and tech angel investor Marc Andreessen as saying, "This is the thing! This is the distributed trust network that the Internet always needed and never had."); Amy Cortese, Blockchain Technology Ushers in the "Internet of Value", CISCO (Feb. 10, 2016), https://newsroom.cisco.com/feature-content?articleId=1741667; Sandeep Soni, After Internet, It's Blockchain Internet 2.0, ENTREPRENEUR (Feb. 5, 2017), https://www.entrepreneur.com/article/288715.

3 See Amelia Lucas, From Ritz. Crackers to McDonald's Salads, Food Recalls - And Safety Questions_Are on the Rise, CNBC (July 29, 2018), https://www.cnbc.com/2018/07/27/ food-recalls-are-increasing-but-that-doesnt-mean-your-food-is-unsafe.html.

4 See Natalie Gagliordi, Walmart Implements IBM's Blockchain for Food Traceability, ZD NET (Sept. 24, 2018), https://www.zdnet.com/article/walmart-implements-ibms-blockchainfor-food-traceability/.

5 See e.g., Frances Katz, Can Blockchain Fix America's Voting System?, THE WeEK (July 17, 2018), http://theweek.com/articles/762519/blockchain-fix-americas-voting-system; Why Online Voting, FollowMrVoTe, https://followmyvote.com/ (last visited Oct. 8, 2018).

6 See How Blockchain Could Change the Global Remittance Industry, FINTECH FuTURES (June 18, 2018), https://www.bankingtech.com/2018/06/how-blockchain-could-change-theglobal-remittance-industry/. 
records, track title to property, or exercise a shareholder vote will likely encounter blockchain in the not too distant future.

Although many people equate blockchain with bitcoin and other cryptocurrencies, this form of distributed ledger technology ${ }^{7}$ also has the potential to transform the way companies look at supply chain optimization, corporate governance, regulatory compliance, and enterprise risk management. While bitcoin first used blockchain and needs it to run, blockchain does not need bitcoin, and in fact, has far greater utility outside of the digital currency realm. ${ }^{8}$

We are in the beginning stages of a shift from the internet of information to the internet of value, where money, financial assets, titles and deeds, intellectual property, and data can be moved, stored, and managed through blockchain technology. $\quad$ In fact, any tangible or intangible asset can be tracked and traded on a blockchain network. ${ }^{10}$ The technology has revolutionary potential because it removes the need for trusted third-party intermediaries such as banks, insurance companies, attorneys, certain government institutions, and companies like Ebay and PayPal to transfer valuable assets from one person to another. ${ }^{11}$ Instead, people using blockchain rely on complex mathematical algorithms and IT infrastructure to eliminate fraud and allow for peer-to-peer transfers. ${ }^{12}$ Early adopter companies and stock exchanges already use blockchain for facilitating more transparent shareholder communications, managing supply chains, providing real time data for internal audit, and increasing

\footnotetext{
7 Some people use the terms "blockchain" and "digital ledger technology" or DLT interchangeably. Blockchain is a type of DLT. See Matthew Beedham, Here's the Difference Between Blockchain and Distributed Ledger Technology, THE NeXt WeB (July 27, 2018), https:/ / thenextweb.com/hardfork/2018/07/27/distributed-ledger-technology-

blockchain/; Shaan Ray, The Difference Between Blockchains \& Distributed Ledger Technology, TOWARDS DATA SCIENCE (Feb. 19, 2018), https://towardsdatascience.com/thedifference-between-blockchains-distributed-ledger-technology-42715a0fa92..

8 See Ray, supra note 7.

9 See Kenny MacIver, From the Internet of Information to the Internet of Value, GLOBAL INTELLIGENCE FOR THE CIO (July 2016), https://www.i-cio.com/big-thinkers/dontapscott/item/from-the-internet-of-information-to-the-internet-of-value.

10 See id.

11 See id.

12 See id.
} 
cybersecurity. ${ }^{13}$ States and central banks, those very entities that some blockchain adherents want to displace, have invested in blockchain research as well. ${ }^{14}$ The United Nations uses blockchain for aid and food distribution and has a number of pilot projects in the works. ${ }^{15}$ Although many worry that the technology will disrupt industries, it will create more jobs in the public and private sector for those with the right skill sets. ${ }^{16}$

Blockchain has a number of benefits for business. First, as Bitcoin inventor Satoshi Nakamoto intended, blockchain allows financial and other transactions without the use of middlemen, thereby reducing cost and delay. ${ }^{17}$ Second, it provides a more secure method of transmitting assets with enhanced privacy protection. ${ }^{18}$ For instance, today, most information is stored centrally. But as recent data breaches have shown, centralized data repositories magnify the risk of data loss. ${ }^{19}$ On a blockchain, however, information is not stored centrally but rather across

${ }^{13}$ Jim Pelletier, A Blockchain Primer for Internal Audit, InTERNAL AudiTOR (Apr. 5, 2018), https://iaonline.theiia.org/blogs/Jim-Pelletier/2018/Pages/A-Blockchain-Primer-forInternal-Audit.aspx.

14 See Central Banks Look to Cash In on Blockchain, GLOBALDATA, https://www. globaldata.com/blockchain-central-banks/ (last visited Jan. 24, 2019); Carlo R.W. De Meijer, Central Banks Apathy for Blockchain is Waning, FinExTRA (Aug. 21, 2018), https://www.finextra.com/blogposting/15678/central-banks-apathy-for-block

chain-is-waning; see generally Blockchain, Cryptocurrencies and Central Banks, Dialogue with the Fed, Beyond Today's Financial Headlines, Federal Reserve BAnK OF SAINT Louis (Aug. 29, 2018), https://www.stlouisfed.org/events/2018/08/dwtf-082918.

15 See Marie Huillet, United Nations Puts Blockchain at Center of New High-Level Panel on Digital Cooperation', COINTELEGRAPH July 13, 2018), https://cointelegraph.com/news/united-nations-puts-blockchain-at-center-of-newhigh-level-panel-on-digital-cooperation; UN Blockchain, MULTI-UN AGENCY PLATFORM, https://un-blockchain.org/ (last visited Jan. 24, 2019).

16 See How Blockchain Could Change the Global Remittance Industry, supra note 6.

${ }^{17} \mathrm{Id}$.

18 See MacIver, supra note 9.

19 See e.g., Dennis Green \& Mary Hanbury, If You Shopped At These 16 Stores in the Last Year, Your Data Might Have Been Stolen, Bus. InSIDER (Aug. 22, 2018), https://www.businessinsider.com/data-breaches-2018-4; Mike Isaac \& Sheera Frenkel, Facebook's Woes Rise as Hackers Expose Data of 50 Million Users, N.Y. TIMES (Sept. 28, 2018), https://www.nytimes.com/2018/09/28/technology/facebook-hack-data-breach.html; Alex Johnson, Equifax Breaks Down Just How Bad Last Year's Data Breach Was, NBC News (May 8, 2018), https://www.nbcnews.com/news/us-news/equifax-breaks-down-justhow-bad-last-year-s-data-n872496. 
a decentralized network of computers around the world..$^{20}$ Third, because participants on the blockchain have real time access to data, blockchain increases transparency while reducing the risk of tampering or deleting data because changes can only be made to the blockchain through a

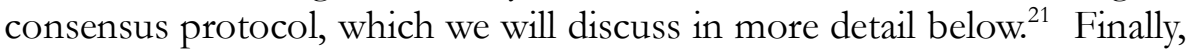
blockchains allow more accurate and faster traceability of assets. ${ }^{22}$ This audit trail reduces the risk of fraud and significantly increases the efficiency of supply chains. ${ }^{23}$

In summary, blockchain benefits business because: (1) it depends on consensus, meaning that all participants agree on a transaction's validity; (2) participants know where the assets came from and who owned it (provenance); (3) the transactions are immutable-participants cannot tamper with the transactions and any corrections are visible to all participants in real time; and (4) it provides finality and a one-stop shop for participants to determine when a transactions is complete. ${ }^{24}$ Blockchain can also assist regulated companies by making it easier for internal and external auditors to access and monitor data and for regulators to verify compliance. ${ }^{25}$

This Article will provide an overview of blockchain technology and then discuss how state and nonstate actors use the technology outside of the realm of cryptocurrency. Part I of this Article will provide an overview of blockchain technology. Part II will briefly describe how public and private actors use blockchain today to track food, address land grabs, protect refugee identity rights, combat bribery and corruption, eliminate voter fraud, and facilitate financial transactions for those without access to banks. Part III will discuss key corporate governance,

20 See A CFTC Primer on Virtual Currencies, LABCFTC 11 (Oct. 17, 2017), https://www.cftc.gov/sites/default/files/idc/groups/public/\%40customerprotection/ documents/file/labcftc_primercurrencies100417.pdf.

${ }^{21}$ Manav Gupta, BlockChain For Dummies 7 (2nd IBM Limited Ed. 2018), available at https://www-01.ibm.com/common/ssi/cgi-bin/ssialias?htmlfid=XIM12354USEN.

22 See How Blockchain Could Change the Global Remittance Industry, supra note 6.

${ }^{23} I d$.

24 GUPTA, supra note 21.

25 Pelletier, supra note 13; Robin La Quercia, How Blockchain is Reshaping External Audit: Crypto Developments by PwC, KPMG, EY and Deloitte, CoINTELEGRAPH (July 26, 2018), https://cointelegraph.com/news/how-blockchain-is-reshaping-external-audit-cryptodevelopments-by-pwc-kpmg-ey-and-deloitte. 
compliance, and social responsibility initiatives that currently utilize blockchain or are exploring the possibility. Part IV will delve more specifically into the business and human rights landscape and examine how blockchain can facilitate compliance. Specifically, we will focus on one of the more promising uses of distributed ledger technologyeliminating barriers to transparency in the human rights arena thereby satisfying various mandatory disclosure regimes and shareholder requests. Part $\mathrm{V}$ will pose questions that board members should ask when considering adopting the technology and will recommend that governments, rating agencies, sustainable stock exchanges, and institutional investors provide incentives for appropriate companies to invest in the technology. Given the increasing widespread use of the technology by both state and nonstate actors and the potential disruptive capabilities, we conclude that firms that do not explore blockchain's impact risk obsolescence or increased regulation.

\section{A BRIEF INTRODUCTION TO CRYPTOCURRENCIES, BLOCKCHAIN, \& SMART CONTRACTS}

Before discussing the use cases and ramifications of blockchain technology, we will provide some context through definition. We will devote most of the discussion in this Article to private or permissioned blockchains and not public blockchains or cryptocurrency. However, because most people read and hear about bitcoin ${ }^{26}$ and cryptocurrency and/or conflate bitcoin and blockchain, we will first provide a high-level overview of bitcoin, public and private blockchains, and smart contracts. ${ }^{27}$

\footnotetext{
26 When discussing the cryptocurrency, we will use "bitcoin." When discussing the specific blockchain that runs bitcoin, we will use "Bitcoin."

27 The discussion that follows provides definitions from several sources. For excellent resources on blockchain and digital ledger technology. See generally Michael J. Casey \& Paul Vigna, In Blockchain We Trust, MIT Tech. Rev. (Apr. 9, 2018), https://www.technologyreview.com/s/610781/in-blockchain-we-trust/; IRS Reminds Taxpayers to Report Virtual Currency Transactions, InTERnAL REVEnUe SERV. (Mar. 23, 2018), https://www.irs.gov/newsroom/irs-reminds-taxpayers-to-report-virtual-

currency-transactions; Antony Lewis, A Gentle Introduction to Blockchain Technology, BRAVENEWCOIN,https://assets.ctfassets.net/sdlntm3tthp6/1N6VBCrkp6oywIooC20o mQ/9b93ac6ac921743a38f80aaeb823a102/A-Gentle-Introduction-To-BlockchainTechnology-WEB.pdf (last visited Jan. 25, 2019); Bernard Marr, A Complete Beginner's Guide To Blockchain, FORBES (Jan. 24, 2017), https://www.forbes.com/sites/ bernardmarr/2017/01/24/a-complete-beginners-guide-to-blockchain/\#747cbe3e6e60.
} 


\section{A. What is Bitcoin?}

To cut through some of the confusion surrounding bitcoin, we need to separate it into two components. On the one hand, there is bitcoin-the-token (digital currency), a snippet of code that represents ownership of a digital concept that is used to store and transfer value. ${ }^{28}$ On the other hand, you have Bitcoin-the-protocol (blockchain), a distributed payment network that maintains a ledger of every transaction of bitcoin-the-token. ${ }^{29}$ The decentralized cryptocurrency bitcoin can be sent directly from user-to-user on the global peer-to-peer Bitcoin network without the need for intermediaries. ${ }^{30}$ A person or group named Satoshi Nakamoto invented Bitcoin in 2008 ${ }^{31}$ and released it in 2009 as free open source software during the financial crisis when trust in large institutions was at its lowest. ${ }^{32}$ Nakamoto wanted to eliminate the need to trust banks or other third-party intermediaries, and as he explained:

[Bitcoin is] completely decentralized, with no central server or trusted parties, because everything is based on crypto proof instead of trust. The root problem with conventional currency is all the trust that's required to make it work. The central bank must be trusted not to debase the currency, but the history of fiat currencies is full of breaches of that trust. Banks must be trusted to hold our money and transfer it electronically, but they lend it out in waves of credit bubbles with barely a fraction in reserve. We have to trust them with our privacy, trust them not to let identity thieves drain our accounts. . . With ecurrency based on cryptographic proof, without the need to trust a third party middleman, money can be secure and transactions effortless. ${ }^{33}$

${ }^{28}$ What is Bitcoin? COINDESK, https://www.coindesk.com/information/what-is-bitcoin (last updated Jan. 26, 2018).

${ }^{29} \mathrm{Id}$.

30 See id.

31 Satoshi Nakamoto, Bitcoin: A Peer-to-Peer Electronic Cash System, (Nov. 1, 2008), www.bitcoin.org/bitcoin.pdf.

32 See Maria Bustillos, The Bitcoin Boom, New Yorker (Apr. 1, 2013), https://www.newyorker.com/tech/annals-of-technology/the-bitcoin-boom.

33 See Bitcoin, P2P FOUND., https://wiki.p2pfoundation.net/bitcoin (last visited Oct. 4, 2018). 
Like Satoshi Nakamoto, Nick Szabo, the inventor of smart contracts, also believed in eliminating governmental interference explaining, "[i]nsecurity drives up costs and gets you stuck inside national silos. [The] biggest reason traditional finance is stuck inside national silos: it depends on governments for its security." ${ }^{\prime 34}$

In addition to removing intermediaries, Bitcoin purports to solve the "double spend problem," which occurs when someone successfully spends the same money more than once. ${ }^{35}$ Bitcoin proponents believe that the double spend problem prevented the widespread use of digital cash in the past and solves that problem by verifying each transaction added to the blockchain to ensure that the inputs for the transaction have not previously been spent. ${ }^{36}$ Bitcoin is by far the most well-known of the over 1,500 cryptocurrencies in existence today ${ }^{37}$ but customers can "cash in" or trade other forms of digital currency through cryptocurrency exchanges. $^{38}$ While bitcoin is not fiat, it must contend with the same valuation concerns as other currencies. Thus, Nakamoto ensured that only 21 million bitcoin can be created or mined; therefore, it is inflation proof. ${ }^{39}$ Accordingly, cryptocurrencies have value in part because it is a finite resource.

Traditionally, fiat money has moved to the most stable currency, ${ }^{40}$ typically the U.S. dollar. However, bitcoin has the advantage of not being controlled by any central authority. ${ }^{41}$ In countries where people are distrustful of how central banks and governments manage the economy,

34 Vicky Cunningham, Nick Srabo on Blockchain and Smart Contracts, YouTuBE (Sept. 7, 2017) at minute 8:50, https://www.youtube.com/watch?v=OkWGtfGKzCY.

35 See id.

36 See id.

37 See All Cryptocurrencies, COINMARKETCAP, https://coinmarketcap.com/all/views/all/ (last visited Oct. 4, 2018).

38 See Latest News on Cryptocurrency Exchanges, COINTELEGRAPH, https://cointelegraph.com/tags/cryptocurrency-exchange (last visited Oct. 8, 2018).

39 See Evelyn Cheng, There Are Now 17 Million Bitcoins in Existence - Only 4 Million Left to 'Mine', CNBC (Apr. 26, 2018), https://www.cnbc.com/2018/04/26/there-are-now-17million-bitcoins-in-existence--only-4-million-left-to-mine.html.

40 Joseph J. Bambara \& Paul R. Allen, Blockchain- A Practical Guide to Developing Business, Law, And Technology Solutions 12 (McGraw Hill Education 2018).

${ }^{41} I d$. 
bitcoin may seem like a more sensible alternative. The second advantage is that bitcoins may be easier to obtain than other fiat currencies. People can buy and sell it via bitcoin exchanges online but also in direct transactions via websites. Evidence suggests that during times of crisis, people are looking to bitcoin as an alternative to their own problematic currencies; for example, as the Greek debt crisis unfolded, bitcoin exchanges reported an increase in volume as people traded the cryptocurrency around the world. ${ }^{42}$

Although blockchain and bitcoin do not need third parties or intermediaries to succeed, that does not mean that government agencies have no interest. The regulation of cryptocurrencies is a hot topic in its own right but is beyond the scope of this Article. Briefly, the IRS regulates bitcoin as property and not currency, ${ }^{43}$ and the CFTC considers bitcoin a commodity. ${ }^{44}$ As of the time of this writing, the SEC does not consider bitcoin a security but has said that initial coin offerings are within its regulatory purview. ${ }^{45}$

\section{B. What is Blockechain?}

While many have focused on the fluctuating values of cryptocurrencies, the underlying technology of digital currency known as blockchain actually has the potential to add significant value anytime data needs to be widely distributed, accurate, and secure. ${ }^{46}$ A blockchain is a historical record of transactions shared across a network of multiple participants. ${ }^{47}$ Think of a blockchain as a mechanism to store data in a decentralized fashion where everyone with access to the chain has the same information updated in real time. The blockchain is a distributed

42 Id.

43 IRS Virtual Currency Guidance, InTERnAL REVEnUE SERV. (Mar. 25, 2014), https://www.irs.gov/newsroom/irs-virtual-currency-guidance.

44 See A CFTC Primer on Virtual Currencies, LABCFTC 11 (Oct. 17, 2017), https://www.cftc.gov/sites/default/files/idc/groups/public/\%40customerprotection/ documents/file/labcftc_primercurrencies100417.pdf; David Felsenthal, Regulation of Bitcoin: The Role of the CFTC, CLIFFORD CHANCE (Jan. 30, 2018), https://www. cliffordchance.com/briefings/2018/01/regulation_of_bitcointheroleofthecftc.html.

45 Bob Pisani, Bitcoin and Ether Are Not Securities, But Some Initial Coin Offerings May Be, SEC Official Says, CNBC (June 14, 2018), https://www.cnbc.com/2018/06/14/bitcoin-andethereum-are-not-securities-but-some-cryptocurrencies-may-be-sec-official-says.html.

46 See Zach Church, Blockechain, Explained, MIT TECH. REV. (May 25, 2017), http://mitsloan.mit.edu/newsroom/articles/blockchain-explained/.

47 See Casey \& Vigna, supra note 27; Church, supra note 46. 
digital ledger ${ }^{48}$ or decentralized database to which data is cryptographically encrypted and recorded sequentially and permanently into smaller data sets called "blocks." 49 Each block averages 1 megabyte and contains control data of approximately 200 bytes - such as a timestamp $p^{50}$ - a link to the previous block, and 1 to $\mathrm{N}$ transactions as can fit in the remaining space. $^{51}$ All participants within a network who have permission to access it have their own identical copy of the ledger. ${ }^{52}$ In a public blockchain, such as Bitcoin or Ethereum, everyone has permission, whereas in a private blockchain, access is limited. ${ }^{53}$ Both types of blockchain use encryption for the chain and the blocks. ${ }^{54}$ Because it is decentralized, theoretically no hacker can exploit the database because there is no central

48 Some use the term "distributed ledger technology" (DLT) interchangeably with the term "blockchain." A blockchain is a type of DLT. A DLT is a system for creating a shared, cryptographically secured database which "(1) enables users to upload programs and to leave the programs to self-execute; (2) maintains a permanent and public record (ledger) of the current and past states of every program; (3) is decentralized; (4) uses public key cryptography for authentication; and (5) uses economic incentives to ensure that the network maintains the technology." Carla L. Reyes, Moving Beyond Bitcoin to an Endogenous Theory of Decentralized Ledger Technology Regulation: An Initial Proposal, 61 VILL. L. REV. 191, 191 n.1 (2016) (citing Vitalik Buterin, Visions, Part 1: The Value of Blockchain Technology, ETHEREum BLOG (Apr. 13, 2015), https://blog. ethereum.org/ 2015/ 04/13/ visions-part-1-the-value-of-blockchain-technology[https://perma.unl.edu/4EJG $\mathrm{KJKA}])$.

49 See Paul H. Farmer, Jr., Note \& Comment, Speculative Tech: The Bitcoin Legal Quagmire \& the Need for Legal Innovation, 9 J. BUS. \& TECH. L. 85, 88-89 (2014).

${ }^{50}$ Timestamping is the process of securely keeping track of the creation and modification time of information. Blockchain technology has made it possible to securely timestamp information in a decentralized and tamper-proof manner. Digital data can be hashed, and the hash can be incorporated into a transaction stored in the blockchain, which serves as a secure proof of the exact time at which that data existed. The proof is due to a tremendous amount of computational effort performed after the hash was submitted to the blockchain. See Nick Grossman, The Blockchain as Verified Public Timestamps, Nick Grossman BlOG (June 15, 2015), https://www.nickgrossman.is/2015/the-blockchainas-time/; see also Jon Buck, Xerox Applies for Blockchain Timestamp Patent, COINTELEGRAPH (Sept. 6, 2017), https://cointelegraph.com/news/xerox-applies-for-blockchaintimestamp-patent (discussing the possibility of irrevocable timestamp protocols for data).

51 Average Blockchain Size, BLOCKCHAIN.ORG, www.blockchain.info/charts/avg-block-size (last visited Dec. 6, 2018).

52 See Marr, supra note 27.

${ }^{53} \mathrm{Id}$.

54 See GUPTA, supra note 21, at 22. 
point of access or control. ${ }^{55}$ Because each transaction can only be recorded once, there is no need for the trusted intermediary to verify that funds exist or that data is accurate. ${ }^{56}$

Each block has a hash, which is like a digital fingerprint, and each hash has a unique value of a fixed length created through a cryptography tool or algorithm. ${ }^{57}$ The hash identifies the block and its contents. ${ }^{58}$ When the block changes, the hash changes, and it is no longer the same block. ${ }^{59}$ Each block contains the hash of the previous block, which helps form the chain. ${ }^{60}$ Bitcoin and many other cryptocurrencies use the proof of work protocol before adding a block to the chain; miners with complex supercomputers prove their work and their entitlement to a reward by solving the problem and generating the hash. ${ }^{61}$

In a public blockchain, blocks are added to the chain after a subset of miners organize valid transactions into blocks, which are time stamped. $^{62}$ These miners race to be the first to solve complex, cryptographic problems using powerful computers called nodes to add newly hashed blocks to a public blockchain. ${ }^{63}$ Many miners create mining farms with several computers so that they can solve the problem first. ${ }^{64}$ Once the miner solves the problem he or she receives cryptocurrency (typically bitcoin) as a reward. ${ }^{65}$ Hackers are deterred because of the

55 See James Bennett, Public vs. Private Blockchain Protocols: What's the Difference?, BRAVE NEW CoIN (Mar. 18, 2018), https://bravenewcoin.com/insights/public-vs-private-blockchain -protocols-whats-the-difference.

56 See Marr, supra note 27.

57 Jake Frankenfield, Hash, INVESTOPEDIA, https://www.investopedia.com/ terms/h/hash.asp (last updated Oct. 20, 2017).

58 See GUPTA, supra note 21, at 14.

${ }^{59} \mathrm{Id}$.

${ }^{60} \mathrm{Id}$.

${ }^{61}$ Frankenfield, supra note 57; see Bitcoin, supra note 33.

62 See Nolan Bauerle, How Does Blockchain Technology Work, COINDESK, https:// www.coindesk.com/information/how-does-blockchain-technology-work/ (last visited Jan. 25, 2019); Michael Abramowicz, Cryptocurrency-Based Law, 58 ARIz. L. REV. 359, 371 (2016).

63 See Bitcoin, supra note 33.

${ }^{64} \mathrm{Id}$.

${ }^{65} \mathrm{Id}$. 
difficulty in solving the cryptographic problems, which also requires a considerable amount of computing power and electricity. ${ }^{66}$ On any given day, bitcoin mining alone uses up as much energy as the nation of Ireland. ${ }^{67}$

Once the miner solves the problem, he or she sends the block to the rest of the node network for approval. ${ }^{68}$ Nodes in the network reach an agreement about a set of data through a consensus protocol. ${ }^{69} \mathrm{After}$ a majority of nodes on the network reach consensus and verify that the hash matches the block, it gets attached to the chain simultaneously. ${ }^{70}$ When someone tries to add a new block to the blockchain, that block is sent to everyone on the network because the ledger is distributed in a peer-to-peer network. ${ }^{71}$ Each node then verifies the block to make sure that it has not been tampered with. ${ }^{72}$ If it is valid, each node adds it to its own blockchain. ${ }^{73}$ Every ten minutes, a new block is added to the Bitcoin blockchain. ${ }^{74}$ Ethereum, another type of public blockchain, adds a new block every fifteen seconds. ${ }^{75}$ The block validation system is designated to be immutable, meaning that all transactions are preserved forever with no ability to delete. ${ }^{76}$ Information can be added to the blockchain after verification through the consensus protocol, but generally, it cannot be

\footnotetext{
66 See Bennett, supra note 55.

67 See Bitcoin, supra note 33.

${ }^{68} \mathrm{Id}$.

69 See Casey \& Vigna, supra note 27; Hyperledger Blockchain Performance Metrics, THE LINUX Foundation PROJECTS - HyPERLEDGER (Oct. 2018), https://www.hyperledger.org/ resources/publications/blockchain-performance-metrics?utm_source $=$ webreferral\&utm_medium=hl-homepage\&utm_campaign=performance-metricswhitepaper\#consensus.

70 See Casey \& Vigna, supra note 27.

${ }^{71} \mathrm{Id}$.

${ }^{72} I d$.

73 See Bitcoin, supra note 33.

${ }^{74} \mathrm{Id}$.

75 See What is Ether, ETHEREUM BLOG, https:/ /www.ethereum.org/ether (last visited Oct. 8, 2018).

76 See Andre Boaventura, Demystifying Blockchain and Consensus Mechanisms - Everything You Wanted to Know But Were Never Told, ORACLE BlOG (Apr. 12, 2018), https://blogs.oracle.com/integration/demystifying-blockchain-and-consensusmechanisms-everything-you-wanted-to-know-but-were-never-told.
} 
altered, deleted, or changed, which increases transparency, traceability, and immutability. ${ }^{77}$ The process reduces fraud because the blocks are linked together, thus changing or tampering with an earlier block would require someone to re-do all of the cryptographic problems of the blocks that follow in the chain. ${ }^{78}$ With a permissionless blockchain, anyone on the network can browse via a designated website and see the ledger. ${ }^{79}$ This in turn provides a way for all participants to have an up-to-date ledger that reflects the most recent transactions. ${ }^{80}$ In this way, blockchain establishes trust, which facilitates transactions and brings many cost saving efficiencies to all types of transactional interactions. ${ }^{81}$ The beauty of a public blockchain, according to its adherents, is that no one person or entity owns or hosts the ledger. ${ }^{82}$

Private blockchains are not open for everyone to be a miner or validator; ${ }^{83}$ they require permission, but do not require the energyintensive proof of work protocol. ${ }^{84}$ Those running the nodes have full control over whom they allow to transact and what transactions can be executed by whom. ${ }^{85}$ The validators of a private chain actually control it and are often kept more centralized to one company or an industry

77 See id.

78 See Bitcoin, supra note 33.

79 See Boaventura, supra note 76.

${ }^{80}$ When used for bitcoin or other cryptocurrency transactions, the blockchain serves as a public ledger.

81 See Boaventura, supra note 76.

82 See Don Tapscott \& Alex Tapscott, Realizing the Potential of Blockchain: A Multistakeholder Approach to the Stewardship of Blockchain and Cryptocurrencies, WORD ECON. FORUM 5 (June 2017), http://www3.weforum.org/docs/WEF_Realizing_Potential_Blockchain.pdf.

83 In the context of a private chain, miners are not necessarily miners because the network is protected in a different way and incentives to operate the network are clear and rooted in off-chain, real world agreements so a mining reward and transaction fees do not make as much sense. Instead, miners are referred to as validators as this is their main remaining function-they validate the proposed blocks coming to the chain. See HenNing Diedrich, Ethereum 194-98 (Wildfire Publ'g 2016).

84 See Praveen Jayachandran, The Difference Between Public and Private Blockchain, Blockchain Pulse: IBM Blockchain Blog (May 31, 2017), https:// www.ibm.com/blogs/blockchain/2017/05/the-difference-between-public-and-privateblockchain.

85 See id. 
consortium. $^{86}$ Users have permission to see all or part of the blockchain depending on the protocols preselected by the company. ${ }^{87}$ This allows for much greater efficiency and transactions on a private blockchain will therefore be completed significantly faster. ${ }^{88}$ Though it does not offer the same decentralized security as its public counterpart, trusting a business to run a blockchain is no more dangerous than trusting it to run a company without blockchain. ${ }^{89}$

In a private or permissioned blockchain, potential uses other than cryptocurrency transactions include speeding up funds settlement, making remittances cheaper and faster, tracking assets, confirming food and mineral provenance, optimizing supply chains, enabling e-notarization, securing digital voting, protecting intellectual property, preventing counterfeit goods, and facilitating records management, which we will discuss in Part II. ${ }^{90}$ Examples of private blockchains include Hyperledger, developed by the Linux Foundation, Quorum from JP Morgan, and Corda from R3. ${ }^{91}$

Another type or derivative of the permissioned blockchain is known as a consortium or federated blockchain, where a group of companies, such as banks, shipping companies, or energy utilities, agree to transact together for certain purposes and allow a percentage of the organizations to validate the transactions. ${ }^{92}$ Typically, only a small group of nodes must verify transactions through a process called "selective endorsement," which eliminates the energy consumption problem of the

\footnotetext{
86 See id.

87 See id.

88 See id.

89 Collin Thompson, The Difference Between a Private, Public, \& Consortium: A Simple Explanation for Dummies, BlockChain Daily News (Oct. 26, 2018), https://www. blockchaindailynews.com/The-difference-between-a-Private-Public-ConsortiumBlockchain_a24681.html.
}

90 See generally Blockchain Fundamentals, PwC GLOBAL BlockChain Survey INFOGRAPHICS (2018), http://explore.pwc.com/blockchain/Infographic-Blockchainfundamentals?WT.mc_id=CT11-PL1000-DM2-TR1-LS4-ND30-TTA5-CN_US-GXxLoSBlockchain-LB-PwCExecSum\&eq=CT11-PL1000-DM2-CN_US-GXxLoSBlockchain-LB-PwCExecSum.

91 See Vitalik Buterin, On Public and Private Blockchains, ETHereum Blog (Aug. 6, 2015), https://blog.ethereum.org/2015/08/07/on-public-and-private-blockchains/; J.P. MORGAN, https://www.jpmorgan.com/global/Quorum (last visited Jan. 25, 2019).

${ }^{2}$ See Bennett, supra note 55. 
public blockchain. ${ }^{93}$ Consensus is controlled by a preselected set of nodes and rules for achieving consensus. ${ }^{94}$ The right to read the blockchain can be open to the public, or it can be restricted to a set of known participants-for example, ten banks in a consortium agree to the consensus rule that seven of the ten banks must sign (approve) a block for it to be considered a valid representation of truth. ${ }^{95}$ A consortium platform provides many of the same benefits affiliated with private blockchain-efficiency and transaction privacy, for example-without consolidating power with only one company. ${ }^{96}$ Further benefits of this type of blockchain include reducing transaction costs and data redundancies while also replacing legacy systems, simplifying document handling, and eliminating semi-manual compliance mechanisms. ${ }^{97}$ More than forty consortia have formed to determine how to use blockchain in

\footnotetext{
93 See Allison Berke, How Safe Are Blockchains? It Depends, HARv. Bus. Rev. (Mar. 7, 2017), https://hbr.org $/ 2017 / 03 /$ how-safe-are-blockchains-it-depends?autocomplete=true; Curtis Miles, Blockchain Security: What Keeps Your Transaction Data Safe?, BlockCHAIN PUlSE: IBM BLOCKCHAIN BlOG (Dec.12, 2017), https://www.ibm.com/ blogs/blockchain/2017/12/blockchain-security-what-keeps-your-transaction-datasafe/. Other consensus mechanisms include: proof of stake, where validators must hold a percentage of the network's total value; multi-signature, where a majority of validators must agree; and practical byzantine fault tolerance, an algorithm used to settle disputes among nodes. See GUPTA, supra note 21, at 16-17. Under proof of authority, however, consensus is achieved by referring to a list of validators (referred to as authorities when they are linked to physical entities). Validators are a group of accounts/nodes that are allowed to participate in the consensus. They validate the transactions and blocks. Proof of authority does not require a mining mechanism involved. Hyperledger and Ripple are based on Proof of Authority. Narayan Prusty, What is Proof-of-Authority Consensus? O'REILLY, https://www.oreilly.com/library/view/building-blockchain-projects/97817 87122147/827f4856-1b32-4a10-a53a-e02050f74a15.xhtml (last visited Jan. 25, 2019).

94 See Berke, supra note 93.

95 Deborah Dobson, The 4 Types of Blockchain Networks Explained, ILTANET (Feb. 13, 2018), https://www.iltanet.org/blogs/deborah-dobson/2018/02/13/the-4-types-ofblockchain-networks-explained?ssopc $=1$.

96 Id.

97 See Blockchain Fundamentals, supra note 90.
} 
their industries. ${ }^{98}$ Some examples of consortium blockchains include R3 (banks) $^{99}, \mathrm{~B} 3 \mathrm{i}$ (insurance) ${ }^{100}$ and EWF (Energy). ${ }^{101}$

In summary, public blockchains are open: anyone can join, become a node, or look at the transactions history via an internet connection. ${ }^{102}$ No one vets the participants who conduct or validate transactions, and therefore a user's identity remains anonymous. ${ }^{103}$ Miners, who validate transactions, expend significant amounts of energy due to the payment incentives required to solve complex algorithms. ${ }^{104}$ On the other hand, private blockchains, used by most companies and governments, require permission to access, the parties know and transact business with each other, and they agree on a consensus protocol that uses a selective validation that does not require incentives to run. ${ }^{105}$ By imposing restrictions, private blockchains have several benefits over public blockchains, such as speed, cost, and control. ${ }^{106}$ "If only specific users can run nodes, [then it is] possible to enforce stringent requirements on

98 See Peter Gratzke, David Schatsky \& Eric Piscini, Banding Together for Blockchain, DeloitTe Insights (Aug. 16, 2017), https://www2.deloitte.com/insights/ us/en/focus/signals-for-strategists/emergence-of-blockchain-consortia.html.

99 Major Banks Partner With R3 Blockchain Alliance to Launch Pilot Trade Platform, COINTELEGRAPH (Feb. 22, 2018), https://cointelegraph.com/news/major-bankspartner-with-r3-blockchain-alliance-to-launch-pilot-trade-platfor; see also Aditi Hudli, Italian Bank Consortium Trials Interbank Transfers on R3's Corda, COINDESK (Oct. 5, 2018), https://www.coindesk.com/italian-banks-complete-blockchain-trial-for-interbank-pay.

100 B3I: The BlockChain Insurance Industry Initiative, https://b3i.tech/ (last visited Jan. 25, 2019).

101 Building the Grids Digital DNA, ENERGY WeB FounD., https://energyweb.org/ (last visited Jan. 25, 2019).

102 See Boaventura, supra note 76.

${ }^{103}$ Blockchains \& Distributed Ledger Technologies, BLOCKCHAINHuB, https://blockchainhub .net/blockchains-and-distributed-ledger-technologies-in-general/ (last visited Feb. 11, 2019).

104 See James Ray, Ethereum Introduction, ETHEREUM WIKI (2018 https://github.com/ ethereum/wiki/wiki/Ethereum-introduction (describing the technical aspects of algorithms).

105 There is a debate about whether permissioned blockchains are actually decentralized or meet the definition at all. See Carla L. Reyes, Conceptualizing Cryptolaw, 96 NEB. L. REv. 384, 390-91 n.29 (2017). This Article recognizes that debate but offers no comment.

106 Joe Coburn, Private v. Public Blockchains: Understanding the Differences, GuIDE (Sept. 17, 2018), https://blocksdecoded.com/public-private-blockchains/. 
processing power and hardware specifications [-] no more long transaction times. Private blockchains can also avoid peak demand during high-profile times." ${ }^{107}$ Transactions are cheaper because they only need to be verified by a few nodes. ${ }^{108}$ The consortium or company running a private blockchain can easily change the rules of a blockchain, revert transactions, modify balances, etc. ${ }^{109}$ For example, in some cases, such as national land registries, this functionality is necessary. Where privacy and control are required, private and consortium blockchains are preferable and where openness is paramount, as well as censorship resistance, then public blockchains are essential. ${ }^{110}$

\section{What is a Smart Contract? ${ }^{111}$}

As discussed above, Ethereum is another type of blockchain, fueled by ether; it has the second largest developer pool and market cap. ${ }^{112}$ Ethereum is a public blockchain system developed by then 19-year-old

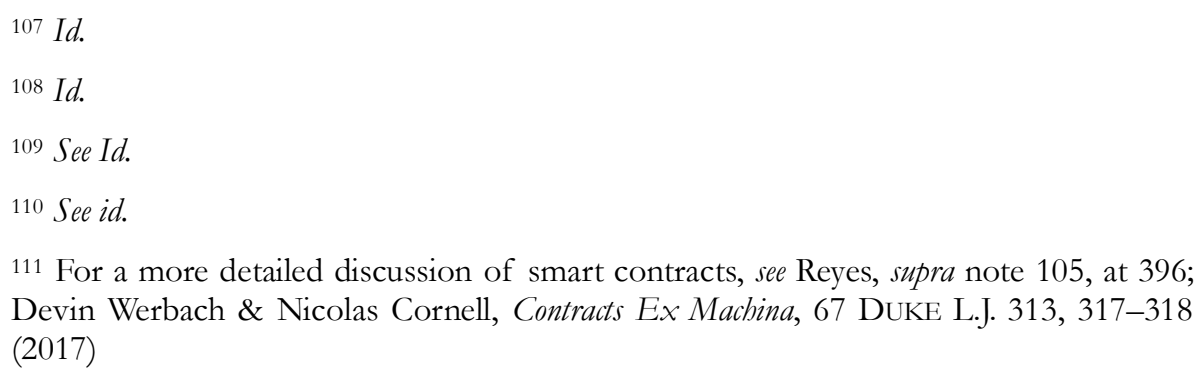

(Smart contracts may or may not transform the world, but they provide real benefits and seem likely to enjoy significant adoption over time.... As they are adopted, or used in lieu of traditional contracting, smart contracts will force courts, legislatures, and other legal actors to confront difficult questions about the application of basic contract doctrines. They will not, however, replace contract law.);

Max Raskin, The Law and Legality of Smart Contracts, 1 GeO. L. TeCH. Rev. 305, 305 (2017) (discussing the benefits of smart contracts for financial transactions, corporate governance, financial products, and other potential applications and recommending that in certain circumstances judges should treat them as traditional agreements); Aaron Wright \& Primavera De Filippi, Decentralized Blockchain Technology and the Rise of Lex Cryptographia, (Mar. 10, 2015), https://ssrn.com/abstract $=2580664$ or http://dx.doi.org/10.2139/ssrn.2580 664 (exploring the benefits and detriments of smart contracts and describing "lex cryptographia" as a new body of contract law); Lee Bacon, Nigel Brook \& George Bazinas, "Smart Contracts:" Where Law Meets Technology, CLYDE\&CO (June 22, 2016), http://www.clydeco.com/insight/article/smart-contractswhere-law-meets-technology.

112 What is Ether, supra note 74. 
Vitalik Buterin ${ }^{113}$ to record not only currency transactions but also the status of computer programs called smart contracts, which are bits of code or computerized instructions to act under an "if/then" protocol. ${ }^{114}$ Smart contracts are not actually contracts at all but the code which allows the automation of contracts. ${ }^{115}$ Ethereum describes smart contracts as "cryptographic 'boxes' that contain value and only unlock it if certain conditions are met." "116

A computer scientist, legal scholar, and cryptography expert named Nick Szabo first conceptualized smart contracts in $1994^{117}$ and published a whitepaper describing them in more detail in 1997. ${ }^{118}$ Szabo

113 See Who is Vitalik Buterin, COINTELEGRAPH, https://cointelegraph.com/ethereumfor-beginners/who-is-vitalik-buterin\#childhood (last visited October 8, 2018).

114 See Blockchain Fundamentals, supra note 90.

115 Eliza MIK, Smart contracts: Terminology, technical limitations and real world complexity, in RES. Collection SCH L., L., InNOvation \& TeCh. 269, 73 (2017), http://ink.library.smu.edu.sg/sol_research/2341.

116 Ethereum White Paper: A Next-Generation Smart Contract and Decentralized Application Platform, GiTHuB, https://github.com/ethereum/wiki/wiki/White-Paper (last updated Jan. 27, 2019); see also James Ray, Design Philosophy, Ethereum Builder's Guide, https://ethereumbuilders.gitbooks.io/guide/content/en/design_philosophy.html (last visited Jan. 25, 2018) (Ethereum markets itself by touting its flexibility:

[A] fundamental part of Ethereum's design philosophy is that Ethereum does not have 'features'. ... Want to invent your own financial derivative? With Ethereum, you can. Want to make your own currency? Set it up as an Ethereum contract. Want to set up a full-scale Daemon or Skynet? You may need to have a few thousand interlocking contracts, and be sure to feed them generously, to do that, but nothing is stopping you.

For more on potential use cases, see J. Dax Hansen \& Carla L. Reyes, Legal Aspects of Smart Contract Applications, PERKINS COIE LLP 2 (May 2017), https://www. virtualcurrencyreport.com/wpcontent/uploads/sites/13/2017/05/Perkins-Coie-LLPLegal-Aspects-of-Smart-Contracts-Applications.pdf.

117 Nick Szabo, Smart Contracts, UNIV. VA. SCH. L. (1994), http://www.fon.hum. uva.nl/rob/Courses/InformationInSpeech/CDROM/Literature/LOTwinterschool200 6/szabo.best.vwh.net/smart.contracts.html.

118 Nick Szabo, Formalizing and Securing Relationships on Public Networks, FIRST MONDAY Vol. II. No. 9-1 (Sept. 1997), http://firstmonday.org/ojs/index.php/ fm/ article/ view/548/469-publisher=First (hereinafter "Szabo whitepaper"); see Vicky Cunningham, Nick Szabo on Blockchain and Smart Contracts, YOUTUBE (2017) at minute 8:50, https://www.youtube.com/watch?v=OkWGtfGKzCY; see also Chamber of Digital Commerce, Nick Szabo - Keynote- Smart Contract Symposium, YouTubE (2016) at minute 5:16, https://www.youtube.com/watch?v $=$ v__$_{-}$mxyN4pcY (where Nick Szabo discusses 
defined a smart contract as "a set of promises, specified in digital form, including protocols within which the parties perform on the other promises." 119 A smart contract is a computerized algorithm, which performs the terms of a contract, however, this definition does not differentiate smart contracts from some already well-known contractual constructs implementing automated performance. ${ }^{120}$ In his famous vending machine analogy, he explained:

Many kinds of contractual clauses (such as collateral, bonding, delineation of property rights, etc.) can be embedded in the hardware and software we deal with, in such a way as to make breach of contract expensive (if desired, sometimes prohibitively so) for the breacher. A canonical real-life example, which we might consider to be the primitive ancestor of smart contracts, is the humble vending machine. Within a limited amount of potential loss (the amount in the till should be less than the cost of breaching the mechanism), the machine takes in coins, and via a simple mechanism, which makes a freshman computer science problem in design with finite automata, dispense change and product according to the displayed price. The vending machine is a contract with bearer: anybody with coins can participate in an exchange with the vendor. The lockbox and other security mechanisms protect the stored coins and contents from attackers, sufficiently to allow profitable deployment of vending machines in a wide variety of areas. Smart contracts go beyond the vending machine in proposing to embed contracts in all sorts of property that is valuable and controlled by digital means. Smart contracts reference that property in a dynamic, often proactively enforced, form and provide much better observation and verification where proactive measures must fall short. ${ }^{121}$

The advent of blockchain and its security protocol made the theoretical possibility of smart contracts come to life. The magic formula

the origins of smart contracts as "a security protocol that changes control of things conditional on performance.").

119 See Nick Szabo, Smart Contracts: Building Blocks for Digital Markets (1996), http://www.alamut.com/subj/economics/nick_szabo/smartContracts.html.

${ }^{120} I d$.

121 Szabo white paper, supra note 118. For his more recent statements and coding suggestions for smart contracts, see e.g., Nick Szabo, A Formal Language for Analyzing Contracts, GEO. WASH. U. (2002), http://www.fon.hum.uva.nl /rob/Courses/InformationInSpeech/CDROM/Literature/LOTwinterschool2006/sza bo.best.vwh.net/contractlanguage.html. 
here is a combination of three powerful effects. A smart contract is an agreement that is binding, as it can move information and digital assets (such as money) around based on the coded concrete terms of the agreement. ${ }^{122}$ It is unstoppable, an automatism that is guaranteed to resolve itself, not relying on a third party for enforcement, but the blockchain instead. ${ }^{123}$ Lastly, it is more precise and arguably easier to read than legal texts, as it is not subject to any interpretation. ${ }^{124}$

While any code can move money, trigger delivery or payment, or effect some other type of exchange of assets, smart contracts are decentralized code that do so only after a condition is fulfilled. ${ }^{125}$ It can be a set of very complex conditions, and there can be interdependencies between smart contracts. ${ }^{126}$ The code can either be extremely short or long running. ${ }^{127}$ The condition can be internal to the blockchain or fed in from the outside real world through an oracle ${ }^{128}$-it does not matter because at some point the conditions will be fulfilled and the contract will automatically execute, i.e., pay out or refund.

Szabo has stated that smart contracts work best with well-defined financial contracts and that they limit the need to work through banks and other middlemen. ${ }^{129}$ Because of the nature of decentralized code, smart contracts can be trusted to do what they are programmed to do without having to trust the humans or corporations behind them. ${ }^{130}$ Therefore,

122 See Nick Szabo, Smart Contracts: Building Blocks for Digital Markets (1996), http://www.alamut.com/subj/economics/nick_szabo/smartContracts.html.

${ }^{123} \mathrm{Id}$.

${ }^{124} \mathrm{Id}$.

${ }^{125}$ MIK, supra note 115.

${ }^{126} I d$.

${ }^{127} I d$.

128 Oracles are data feeds from external systems that feed vital information into blockchains that smart contracts may need to execute under specific conditions. Oracles can be services that give out digital proof for any event that happened, such as Oraclize, Reality Keys and Chainlink. See BLOCKONOMI, https://blockonomi.com/oracles-guide/ (last visited Jan. 22, 2019).

${ }^{129}$ Swiss Re, Nick Szabo: Global Financial Assets on Bitcoin, blockchain, and the Benefits of Smart Contracts, YOUTUBE (2016), https://www.youtube.com/watch?v=vXCOfTteQAo.

${ }^{130} I d$. 
smart contracts are more fair, accurate, easier to vet, have lower execution risk, and are cheaper than existing intermediary structures. ${ }^{131}$

However, lawyers have pointed out a number of limitations with smart contracts, ${ }^{132}$ including enforceability issues, concerns about ambiguous terms such as "reasonable," and the fact that if the code is wrong or parties fail to review the code, the contract will not function as intended. ${ }^{133}$ Additionally, amending the contract would require amending the code. ${ }^{134}$ Law firm Perkins Coie has provided a list of issues for firms considering smart contracts, asking, among other things: whether the contract will replace a governmental function; what other laws apply; whether warnings or instructions should be required; what protocols or monitoring systems exist to guard against coding biases; what provisions exists to limit liability and provide for indemnification; and how will privacy issues be addressed. ${ }^{135}$ Notwithstanding these concerns, many of the permissioned or private blockchains already use smart contracts in implementation.

Like any new technology, there are benefits and risks to smart contracts. As discussed above, the benefit of a decentralized technology such as blockchain is that it provides a more trustworthy ledger, as opposed to a centralized database, and it offers immutability, security via encryption, traceability and transparency of records and transactions for participants, as well as lower operational costs. The combination of smart

131 Id.

132 See Stuart D. Levi and Alex B. Lipton, An Introduction to Smart Contracts and their Potential and Inherent Limitations, SkAdDEN, ARPS, Slate, MEAgHer \& Flom LLP (May 7, 2018), https://www.skadden.com/insights/publications/2018/05/an-introduction-to-smartcontracts (last visited October 8, 2018) (noting,

[s]mart contracts are presently best suited to execute automatically two types of "transactions" found in many contracts: (1) ensuring the payment of funds upon certain triggering events and (2) imposing financial penalties if certain objective conditions are not satisfied. In each case, human intervention, including through a trusted escrow holder or even the judicial system, is not required once the smart contract has been deployed and is operational, thereby reducing the execution and enforcement costs of the contracting process.

) .

133 See Id.

134 Id.

135 Hansen \& Reyes, supra note 116, at 16. 
contracts with blockchain adds autonomy, certainty, and resilience while also lowering counterparty risk. Moreover, the information stored on the blockchain is protected from security threats as it is maintained on multiple nodes where more than fifty-one percent of the nodes would have to be compromised before any problematic issue would manifest such as manipulation or collapse. ${ }^{136}$ These qualities of blockchain and smart contracts make this technology so applicable to numerous industries and so attractive to enterprises, as well governments.

\section{Blockchain Use Cases for Private Enterprise AND STATE ACTORS}

Although many projects are still in the beta testing stage, developers envision using blockchain technology, in particular smart contracts, for everything from corporate bond transfers ${ }^{137}$ to travel insurance $^{138}$ to leasing vehicles. ${ }^{139}$ Eighty-two percent of retailers surveyed believe that blockchain can reduce costs and raise efficiencies. ${ }^{140}$ In this Part, we will briefly describe how public and private actors use blockchain today to track food, address land grabs, protect refugee identity rights, combat bribery and corruption, eliminate voter fraud, and facilitate financial transactions for those without access to banks.

\section{A. Food and Drug Supply}

Tracking food and drugs in the supply chain is perhaps one of the most significant use cases of permissioned blockchains. Blockchain and smart contracts can provide real-time visibility for every step in a supply chain. Internet of Things devices can record each step as a product moves from a factory floor to the store shelves. This technology facilitates granular-level inventory tracking, benefitting supply chain financing,

136 See 51\% Attack, InVESTOPEDIA (July 5, 2018), https://www.investopedia.com/ terms/1/51-attack.asp.

137 See Bond Case Study in Asset Settlement Using Blockchain Technology, SAwTOOTH DisTRIBUTED LEDGERS (2015-2017), https://sawtooth.hyperledger.org/examples /bond.html.

138 See Dual Layered Protocol for Financial Assets White Paper, PAL Network 21-23 (Oct. 2018), https://www.pal.network/whitepaper/PAL_WhitePaper.pdf.

139 See IBM Blockchain Car Lease Demo, IBM Developer (May 29, 2018), https://developer.ibm.com/tv/ibm-blockchain-car-lease-demo/.

${ }^{140}$ Robert Weldon, Matthew Herridge, \& Julie Cohen, Retail: Opening the Doors to Blockchain, COGNIZANT REPORTS 4 (July 2017), https://www.cognizant.com/ whitepapers/retailopening-the-doors-to-blockchain-codex2879.pdf. 
insurance, and risk. Such enhanced tracing and verification reduce the risk of theft and fraud. In one of the largest initiatives, the IBM Food Trust offers tiered plans for companies to use end-to-end traceability and certifications in the supply chain. ${ }^{141}$ On September 24, 2018, one of the original members of the Food Trust-Walmart-sent a letter ${ }^{142}$ to its leafy green suppliers requiring them to be on its blockchain platform by 2019 so that the company can track the origin of food from the farm in seconds and not days through paper ledgers. ${ }^{143}$ French retailer Carrefour has also signed on to use IBM's technology to track its chicken, eggs, and tomatoes from the supplier to the store. ${ }^{144}$ Restaurants are also harnessing the power of blockchain. Bloomin' Brands is testing a solution that will allow it to manage its supplies in the event of a recall related to food safety, while Sweetgreen is using Ripe.io's technology to track the tomatoes it uses from farm to restaurant. ${ }^{145}$

The Centers for Disease Control, a U.S. government agency, supports the use of the technology explaining,

[e]nhanced ability to trace a contaminated food back to its source will help government agencies and companies to

${ }^{141}$ IBM Food Trust Expands Blockchain Network. to Foster a Safer, More Transparent and Efficient Global Food System, IBM News RoOM (Oct. 8, 2018), https://newsroom.ibm.com/201810-08-IBM-Food-Trust-Expands-Blockchain-Network-to-Foster-a-Safer-More-

Transparent-and-Efficient-Global-Food-System-1; see generally, IBM FOOD TRUST, https://public.dhe.ibm.com/common/ssi/ecm/89/en/89017389usen/ibmfoodtrust_s olutionbrief2_89017389USEN.pdf (last visited Jan. 20, 2019).

${ }^{142}$ Charles Redfield, Russell Mounce, Martin Mundo \& Frank Yiannis, Food Traceability Initiative Fresh Leafy Greens, WALMART NEWS ROOM, https://corporate.walmart.com /media-library/document/blockchain-supplier-letter-september-

2018/_proxyDocument?id=00000166-088d-dc77-a7ff-4dff689f0001 (last visited Jan. 20, 2019).

143 Matt Smith, In Wake of E. coli Scare, Walmart Deploys Blockchain to Track Leafy Greens, WALMART COMMUNICATIONS, https://news.walmart.com/2018/09/24/in-wake-ofromaine-e-coli-scare-walmart-deploys-blockchain-to-track-leafy-greens (last visited Jan. 20, 2019).

144 Tom Wilson \& Eric Auchard, Chickens and eggs: Retailer Carrefour adopts blockchain to track fresh produce, REUTERS (Oct. 8, 2018), https://www.reuters.com/article/us-carrefourblockchain-ibm/chickens-and-eggs-retailer-carrefour-adopts-blockchain-to-track-freshproduce-idUSKCN1MI162

${ }^{145}$ Kevin Hardy, Explaining the Rise of Blockchain in Restaurants, QSR MAGAZINE (July 2018), https://www.qsrmagazine.com/technology/explaining-rise-blockchainrestaurants 
identify the source of a foodborne disease outbreak, coordinate more effective recalls of foods thought to be contaminated, and learn where past problems began. We think these steps will strengthen future prevention efforts and better protect the public's health from the threat of foodborne illness. ${ }^{146}$

Walmart conducted a test in which they traced a package of sliced mangoes from the store shelf back to the farm, the company explained. ${ }^{147}$ Under traditional methods, this trace took more than six days. ${ }^{148}$ Using IBM Food Trust, the company could identify the exact source of the fruit in 2.2 seconds. ${ }^{149}$ If effectively implemented across the supply chain, blockchain could improve food recall processes because of the ease and speed with which food can be traced to both its origin and its destination. When tracked immediately, grocers and restaurants could account for the recall-affected items and remove them from shelves or menus.

Blockchain also has utility in tracking pharmaceuticals. The World Health Organization estimates that ten percent of drugs found in low to middle income countries are counterfeit, which that leads to tens of thousands of people with diseases who die after taking medication. ${ }^{150}$ For these reasons, the U.S. Food and Drug Administration wants to make it easier to track contaminated or counterfeit medicines. ${ }^{151}$ Under the agency's Drug Supply Chain Security Act, companies must be able to accurately track their supply chains by 2023 through a national track-andtrace system by which manufacturers must affix product identifiers to

\footnotetext{
146 Smith, supra note 143.

147 Jessica McKenzie, Why Blockchain Won't Fix Food Safety-Yet, THE New FOOD ECONOMY (Feb. 4, 2018), https://newfoodeconomy.org/blockchain-food-traceabilitywalmart-ibm/.

${ }^{148} I d$.

${ }^{149} I d$.

150 Substandard and Falsified Medical Products, World Health Organization (Jan. 31, 2018), http://www.who.int/news-room/fact-sheets/detail/substandard-and-falsifiedmedical-products.

151 See Title II Drug Supply Chain Security ACt \581 (2018), available at https://www.fda.gov/Drugs/DrugSafety/DrugIntegrityandSupplyChainSecurity/Drug SupplyChainSecurityAct/ucm376829.htm.
} 
each package or product introduced into the supply chain. ${ }^{152}$ Some of the largest pharmaceutical companies in the world have partnered together to contribute to a pilot program exploring blockchain for compliance. $^{153}$

\section{B. Healthcare ${ }^{154}$}

Blockchain may also revolutionize healthcare by increasing accessibility to patient records that are currently scattered among different providers using outdated systems; providing more secure transactions and minimizing data breaches; allowing governments and doctors to access anonymized data for research trials; reducing insurance fraud; and improving interoperability among disparate data systems. ${ }^{155}$ In fact, the

152 See Title II Drug Supply Chain Security Act \581 (2018), available at https://www.fda.gov/Drugs/DrugSafety/DrugIntegrityandSupplyChainSecurity/Drug SupplyChainSecurityAct/ucm376829.htm.

153 See Edwin Lopez, Big Pharma builds blockchain prototype to stop counterfeits, SUPPLY CHAIN Dive (Sept. 21, 2017), https://www.supplychaindive.com/news/big-pharmablockchain-MediLedger-DSCSA-FDA/505563/.

${ }^{154}$ For a more detailed discussion of the use of blockchain in healthcare, see Alevtina Dubovitskaya et al., Secure and Trustable Electronic Medical Records Sharing using Blockchain, AMIA AnN. Symp. Proc. ArChive (Apr. 16, 2018), https://www.ncbi.nlm.nih.gov/ pmc/articles/PMC5977675/; Thomas Heston, Why Blockchain Technology Is Important for Healthcare Professionals, ElsOn S. Floyd C. MED. \& U. WASH. (July 20, 2017), https://ssrn.com/abstract=3006389 (

The next major advance in medical records is not going to be a new software program that runs on a database isolated within a single healthcare organization. The next advance will be the creation of a distributed ledger which will effectively transfer control of patient records from the healthcare organization to the individual. When medical records become as freely mobile as people, we will have made a tremendous leap forward in medicine.

); Shackelford, Scott J. et. al, Securing the Internet of Healthcare, 19 MINN. J.L. SCI. \& TECH. 405, 408 (2018) (" $[$ W]e propose that blockchain is a useful tool to help healthcare providers and manufactures mitigate certain supply chain and security risks but only as part of a larger universe of reforms needed to secure the Internet of Healthcare."); Marc Pilkington, Can Blockchain Improve Healthcare Management? Consumer Medical Electronics and the IoMT, U. BOuRgOGNE FrAnCHE COMTÉ (Aug. 24, 2017), at 7, https://ssrn.com/ abstract $=3025393$ (" $[\mathrm{H}]$ ealthcare services are shifting from a centralized, hospitaloriented model towards a distributed patient-centric model. It is this distributed nature that makes it all the more relevant for future blockchain applications.")

155 See Bill Siwicki, How Blockchain can help with healthcare's patient matching problem, HEALTHCARE IT NEws (Aug. 13, 2018), https://www.healthcareitnews.com /news/ how-blockchain-can-help-healthcares-patient-matching-problem; Randy Bean, Will 
field is so promising that researchers have established a journal to share their learnings on blockchain. ${ }^{156}$ Additionally, a number of consulting firms are working with companies that plan to use blockchain to manage patient data in clinical trials and electronic health records. ${ }^{157}$ Blockchain fits naturally with healthcare reform because a decentralized system may increase security while at the same time improving access controls and making it more difficult to tamper with or change records without authorization.

However, despite the promise, a number of key questions remain, as Professor Charlotte Tschider has observed. ${ }^{158}$ First, will gains in cybersecurity protection outweigh privacy or other legal issues such as data ownership? ${ }^{159}$ Second, what would be the practical implications of implementing a private blockchain whether through a consortium, patient-initiation, regulatory-approval ${ }^{160}$ Third, how could blockchain work with other medical device applications? ${ }^{161}$ Finally, how would the technology work over geographic regions with different regulatory structures, especially as it relates to data protection? ${ }^{162}$ These questions will hopefully be answered or at least contemplated as companies like Gem Health partner with Philips to explore how blockchain technology can support a patient centric-approach to healthcare ${ }^{163}$ and MedRec

Blockchain Transform Healthcare?, FORBES MAGAZINE (Aug. 5, 2018), https://www.forbes.com/sites/ ciocentral/2018/08/05/will-blockchain-transformhealthcare/\#191f01ab553d;

156 See generally Patrick Li et al., DMMS: A Decentralized Blockchain Ledger for the Management of Medication Histories, BlockChain In HealthCare Today (Mar. 23, 2018), https://blockchainhealthcaretoday.com/index.php/journal.

157 See e.g., Blockchain in Healthcare, BlOCKCHAIN UnLEASHED: IBM BlOCKCHAIN BLOG, https://www.ibm.com/blogs/blockchain/category/blockchain-in-healthcare/ (last visited Jan. 20, 2019); see also RJ Krawiec et al., Blockchain: Opportunities for health care, DELOITTE, https://www2.deloitte.com/us/en/pages/public-sector/articles/ blockchain-opportunities-for-health-care.html (last visited Jan. 20, 2019).

158 Charlotte A. Tschider, Blockchain in Healthcare Panel, SEALS CONF. (Aug. 2018).

${ }^{159} \mathrm{Id}$.

${ }^{160} \mathrm{Id}$.

${ }^{161} \mathrm{Id}$.

${ }^{162} I d$.

163 See Health, GEM ENTERPRISE, https://enterprise.gem.co/health/ (last visited Jan. 20, 2019). 
embarks on a pilot project with Beth Israel Deaconness Medical Center to create a decentralized content-management system for healthcare data. ${ }^{164}$ Though there are certain concerns and speculations regarding blockchain's integration with current healthcare systems and its cultural adoption, it is clear this new technology creates unique opportunities to reduce complexity, enable trustless collaboration, and create secure and immutable information, which has widespread implications for stakeholders in the healthcare ecosystem. ${ }^{165}$

\section{Banking and Finance}

One of the most talked-about topics in the financial services industry today is blockchain because of the benefits and features it can provide, some of these being faster throughput, reduced costs, less room for error, reliability, transparency, and auditability. The financial institutions that find ways to adopt and apply blockchain technology will gain the competitive advantage of delivering solutions with faster time-tomarket at a reduced cost. "With global banking currently a $\$ 134 \mathrm{~T}$ industry, blockchain technology and DLT could disintermediate key services that banks provide, including:" ${ }^{166}$ Know Your Customer (KYC), clearance and settlement systems, global payments, securities, and trade finance.

Accenture has estimated that the biggest investment banks could save $\$ 10$ billion by using blockchain technology to improve the efficiency of clearing and settlement. ${ }^{167}$ Richard Lumb, head of financial services at the consultancy, has predicted: "The first place we will see it have an impact is clearing houses, such as Deutsche Börse, the Australian Stock Exchange and Depository Trust \& Clearing Corporation [DTCC]." ${ }^{168} \mathrm{He}$ added: "Today it is managed through a myriad of messages and manual

164 Ariel Ekblaw et al., MedRec: A Case Study for Blockchain in Healthcare, MIT DigITAL CURRENCY INITIATIVE (Aug. 2016), https://dci.mit.edu/research/blockchain-medicalrecords.

165 Krawiec et al., supra note 157.

166 How Blockchain Could Disrupt Banking, CBS INSIGHTS (Dec. 12, 2018), https://www.cbinsights.com/research/blockchain-disrupting-banking/.

167 Banking on Blockchain: A Value Analysis for Investment Banking, ACCENTURE, https:// www.accenture.com/t20170120T074124Z__w_/usen/_acnmedia/Accenture/Conver sion-Assets/DotCom/Documents/Global/PDF/Consulting/Accenture-Banking-on Blockchain.pdf\#zoom $=50$ (last visited Jan. 20, 2019).

168 Martin Arnold, Five Ways Banks are Using Blockchain, FIN. TIMES (Oct. 16, 2017), https://www.ft.com/content/615b3bd8-97a9-11e7-a652-cde3f882dd7b. 
reconciliation. There is a big opportunity for blockchain to seriously restructure that industry." ${ }^{169}$ One of the best-known examples of this restructuring is the Australian Securities Exchange, which aims to shift much of its post-trade clearing and settlement on to a blockchain system. ${ }^{170}$ In the United States, DTCC is working with IBM, R3, and Axoni to shift post-trade clearing of single-name credit default swaps on to a blockchain system by the end of next year. ${ }^{171}$

The global payments business is a large, slow, costly, and errorprone industry, which makes it another candidate for blockchain innovation. It can be expensive and take days to transfer money from a party in one country to a party in another country. By establishing a decentralized ledger for payments (e.g. Bitcoin and Ripple), blockchain technology could facilitate faster payments at lower fees than banks. Blockchain technology offers a high-security, low-cost way of sending payments that cuts down on the need for verification from third parties and beats processing times for traditional bank transfers. Some companies are using blockchain technology to improve cross-border payments in developing economies. BitPesa, for example, focuses on facilitating B2B payments in countries like Kenya, Nigeria, and Uganda. ${ }^{172}$ Companies like Ripple are working with numerous Japanese banks to create efficient cash transfers through the application of blockchain technology. ${ }^{173}$

By tokenizing traditional securities such as stocks, bonds, and alternative assets-and placing them on public blockchains-blockchain technology could also create more efficient, interoperable capital markets.

${ }^{169} I d$.

170 David Floyd, ASX Exchange Targets 2020 for DLT Settlement System, CoINDESK (Apr. 30, 2018), https://www.coindesk.com/australian-securities-exchange-eyes-end-2020-dltrollout.

${ }^{171}$ Kristi Morrow, DTCCC Selects IBM, Axoni, and R3 to Develop DTCC Distributed Ledger Technology Solution for Derivatives Processing, DTCC (Jan. 9, 2017), http://www.dtcc.com/ news/2017/january/09/dtcc-selects-ibm-axoni-and-r3-to-develop-dtccs-distributedledger-solution.

172 The company claims to have processed millions of dollars in transactions, reportedly growing 20\% month-over-month. See BitPesa 5 th Anniversary: Celebrating 5 years of Growth, BITPESA (Nov. 19 2018), https://www.bitpesa.co/blog/bitpesa-anniversary-5-years-ofgrowth/\#.

${ }^{173}$ Ryan Browne, Ripple Develops Blockchain Payment App with Japanese Bank Consortium, CNBC (Mar. 7, 2018), https://www.cnbc.com/2018/03/07/ripple-develops-blockchain -payment-app-with-japanese-bank-consortium.html. 
Securities and stock trading currently require structured deals for offerings and require many intermediaries to have access to and validate information between the pre-trade and post-trade reporting and various servicing elements. ${ }^{174}$ Blockchain could reduce the overhead 'required' in these transactions, reduce the time to provide information to all of the parties involved, and simplify reporting, because all of the information and ownership would be in available to the parties that needed it (including the ownership of partial shares, which could be broken out as a portion of a block). ${ }^{175}$

For example, the Nasdaq Stock Market worked with Chain.com to issue securities on the Nasdaq Linq blockchain ledger technology in 2015. ${ }^{176}$

Trade finance commonly involves multiple parties across various parts of a deal to complete their part before funding events happen. When done internationally or as part of very large deals, there can be a number of intermediaries involved in validating that each party has met the obligations of the contract. ${ }^{177}$ In March 2017, global shipping company Maersk announced it had completed a test that leveraged blockchain technology built in partnership with IBM to track freight shipments, allowing better security, less paperwork, and better access to information by parties such as the Department of Homeland Security. ${ }^{178}$ Additionally, seven European banks announced a partnership with IBM to build a cross-border trade finance blockchain. ${ }^{179}$ By replacing the cumbersome, paper-heavy bills of lading process in the trade finance

174 See Peter Andrew Davey, Is Blockchain Technology Right for Banking, THE CLEARING HOuSE, https://www.theclearinghouse.org/banking-perspectives/2017/2017-q4banking-perspectives/articles/blockchain-for-banking (last visited Jan. 20, 2019).

${ }^{175} \mathrm{Id}$.

176 See Nasdaq Linq Enables First- Ever Private Securities Issuance Documented with Blockchain, NASDAQ (Dec. 30, 2015), http://ir.nasdaq.com/news-releases/news-release-details/ nasdaq-linq-enables-first-ever-private-securities-issuance?releaseid=948326.

177 Davey, supra note 174.

178 Tom Groenfeldt, IBM and Maersk Apply Blockchain to Container Shipping, FORBES (Mar. 5, 2017), https://www.forbes.com/sites/tomgroenfeldt/2017/03/05/ibm-and-maerskapply-blockchain-to-container-shipping/\#57f8e45a3f05.

179 Tom Groenfeldt, 7 European Banks Form Blockchain Consortium for SME's, Forbes (June 28, 2017), https://www.forbes.com/sites/tomgroenfeldt/2017/06/28/7-europeanbanks-form-blockchain-consortium-for-smes/\#49d8f3d93818. 
industry, blockchain technology can create more transparency, security, and trust among trade parties globally.

\section{Supply Chain and Logistics}

Prior to using the blockchain platform, Maersk estimated that it could take 30 people or organizations and 200 documents or interactions to process a shipment of refrigerated goods from one part of the world to another. ${ }^{180}$ Maersk is the largest container shipping company in the world and has twenty percent of the global shipping market. ${ }^{181}$ After developing the proof of concept, Maersk and IBM announced TradeLens, a collaborative venture with over 90 participants who constitute more than twenty percent of the global supply chain. ${ }^{182}$ The platform uses custom smart contracts to execute transactions with fewer intermediaries. ${ }^{183}$ Although the solution shows promise, many of Maersk's largest competitors have failed to join the initiative over concerns about usability and Maersk's ownership of the IP. ${ }^{184}$ In theory, Maersk's competitors would act as "trust anchors" running full blockchain nodes on the network. ${ }^{185}$ Because large shippers use multiple carriers and freightforwarders, the solution only works if multiple participants manage the cargo and inventory across the different networks. ${ }^{186}$ Ironically, it appears as though a lack of trust may prevent this blockchain initiative from reaching its full potential.

On the other hand, the competitors that make up the Blockchain in Transportation Alliance (BITA) see tremendous potential in the technology and in partnering with each other. ${ }^{187}$ This industry group of hundreds of fleet managers, third-party logistic providers, shippers, original equipment manufacturers, technology companies, investors,

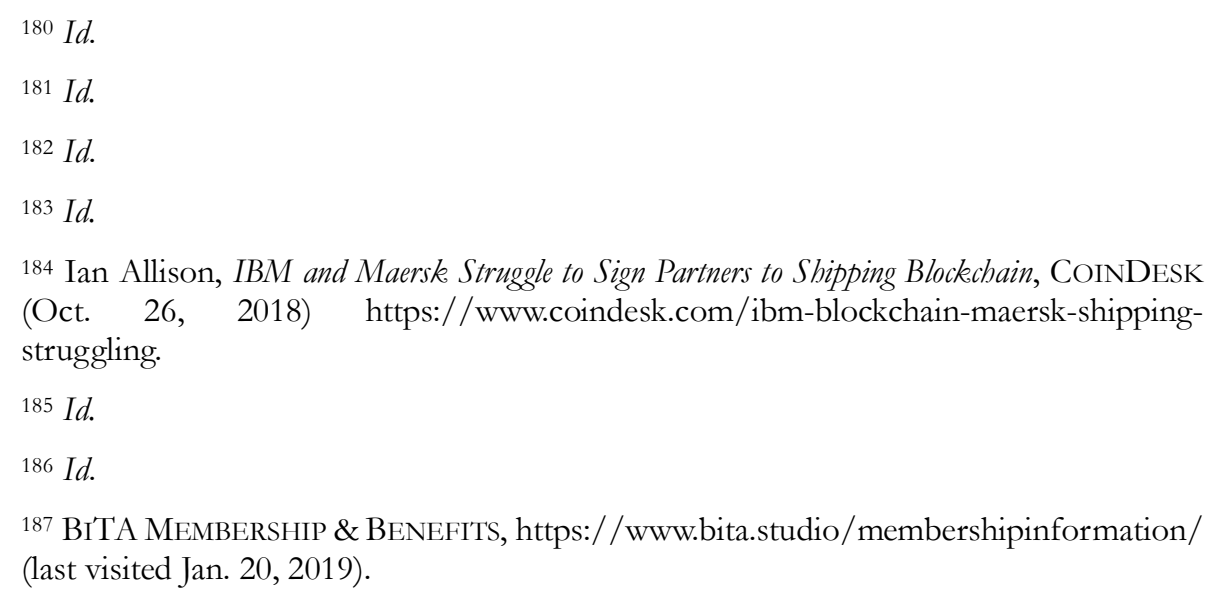


suppliers, and vendors aims to explore the design and adoption of blockchain standards. ${ }^{188}$ Member companies include FedEx, UPS, Target, Whirlpool, Google, pWc, Cisco, HP, Microsoft, Ryder, Deloitte, BP Oil, and Anheuser Busch. ${ }^{189}$ In addition, SAP, a member of BITA, has also created a consortium of two dozen food, pharmaceutical, technology, and shipping companies to pilot a cloud-based tracker for goods from creation to shipment using blockchain. ${ }^{190}$ UPS has filed for a patent ${ }^{191}$ to track shipments on multiple carriers and optimize routes with limited human intervention. ${ }^{192}$ FedEx's CEO Fred smith has called the technology the "next frontier" in logistics and has joined the Hyperledger open source platform to collaborate cross-industry blockchain projects. ${ }^{193}$ Finally, companies such as SAP, IBM, Microsoft, and Amazon clearly see blockchain as a service as a lucrative business opportunity, particularly related to supply chains. ${ }^{194}$

\section{E. State Actors}

"Currently governments on all continents except Antarctica are engaged in blockchain pilot projects." ${ }^{195}$ According to an IBM survey of two hundred governmental executives in sixteen countries, nine out of ten

188 Id.

189 BITA MEMBERS, https://www.bita.studio/members/ (last visited Jan. 20, 2019).

190 SAP BLOCKCHAIN APPLICATIONS, https://www.sap.com/products/leonardo/ blockchain.html\#customers (last visited Jan. 20, 2019).

191 U.S. Patent Application No. 15/932328 (filed Feb. 16, 2018), available at http://appft.uspto.gov/netacgi/nphParser?Sect1=PTO1\&Sect2=HITOFF\&d=PG0\&

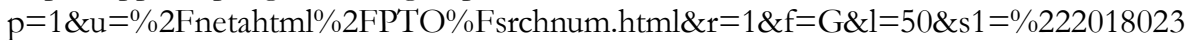
2693\%22.PGNR.\&OS=DN/20180232693\&RS=DN/20180232693.

192 See Emma Cosgrove, UPS Blockchain Patent Aims to Route Packages on Multiple Carriers, SuPPlyChAINDive (Aug. 20, 2018), https://www.supplychaindive.com/news/upsapplies-blockchain-patent-multiple-carriers/530467/.

193 'Thomas Black, FedEx CEO Fred Smith Sees Blockchain as Next Frontier' for Logistics, BloOmberG NEws (May 16, 2018), https://www.ttnews.com/articles/fedex-ceo-fredsmith-sees-blockchain-next-frontier-logistics.

194 Lucas Mearian, Blockchain to Generate More Than $\$ 10.6 B$ in Revenue by 2023, COMPUTERWORLD (Oct. 18, 2018), https:/ /www.computerworld.com/

article/3237465/enterprise-applications/blockchain-to-generate-more-than-106b-inrevenue-by-2023.html.

195 Jorden Woods, Blockechain: Public Sector Use Cases, MEDIUM (Oct. 2, 2018), https://www.computerworlduk.com/galleries/applications/how-governments-areusing-blockchain-3680393. 
governmental institutions surveyed expect to invest in blockchain in 2018 and seven in ten government executives expect blockchain will deliver the greatest cost, time, and risk reduction benefits in regulatory compliance. ${ }^{196}$ Other areas that the public sector plan to use blockchain include government records, citizen services, and identity management. ${ }^{197}$ Across these use cases, blockchain enables greater efficiency, less fraud, and lower costs. ${ }^{198}$ "The holy grail is fully paperless, digital government with minimal corruption." 199

\section{Land Title Registries}

To understand the potential of a blockchain land registry system, one must first understand how property changes hands. When a purchaser seeks to buy property today, he or she must find and secure the title and have the lawful owner sign it over. This seems simple on the surface, but the devil is in the details. For a large number of residential mortgage holders, flawed paperwork, forged signatures, and defects in foreclosure and mortgage documents have marred proper documentation of property ownership. The resulting situation means that the property no longer has a "good title" attached to it and is no longer legally sellable, leaving the prospective buyer in many cases with no remedies. Land registry blockchains seek to fix these "problems eminent in the traditional registry: corruption and extensive property fraud in the international markets, cross-border barriers, slow registration processes, double registrations or ownership, and 'dead capital' of unrecorded land in developing countries. ..."200

Although many registries currently outside of blockchain utilize online land registry processes, there is still some amount of manual processes to undertake, including payment. ${ }^{201}$ Smart contracts facilitate transfer of titles automatically by means of tech rules once funds are

196 Building Trust in Government: Exploring the Potentials of Blockechain, IBM INST. FOR BUS. VALUE 2 (Jan. 2017), https://public.dhe.ibm.com/common/ssi/ecm/gb/en/gbe03801 usen/gbe03801usen-01_GBE03801USEN.pdf.

${ }^{197} \mathrm{Id}$.

198 Woods, supra note 195.

${ }^{199} \mathrm{Id}$.

${ }^{200}$ David Kariuki, Blockchain-Based Land Registry Systems Can Help Eliminate Fraud, Corruption and Delays, CRYPTOMORROw (Feb. 27, 2018), https://www.cryptomorrow.com /2018/02/27/blockchain-based-land-registry-and-record-systems/.

${ }^{201} \mathrm{Id}$. 
transferred. ${ }^{202}$ It speeds the transaction and registration. ${ }^{203}$ Most of these registries are also not secure compared to blockchain that secures data using cryptography. ${ }^{204}$

By using hashes to identify every real estate transaction (thus making it publicly available and searchable), proponents argue issues such as who is the legal owner of a property can be remedied. 'Land registry records are pretty reliable methods for maintaining land records, but they are expensive and inefficient,' David Reiss, professor of law and academic program director at the Center for Urban Business Entrepreneurship, told CoinDesk. He [further] explained, 'There is good reason to think that blockchain technology could serve as the basis for a more reliable, cheaper and more efficient land registry. ${ }^{205}$

Within the United States, the city of South Burlington, Vermont, is trialing a land registration system utilizing blockchain for recording and authenticating property ownership, ${ }^{206}$ and "[l] ast year the office of the Cook County recorder of deeds participated in a pilot project that explored the barriers to adopting blockchain and the potential gains from overcoming those barriers."207 Outside the United States, problems with land titles are even more pronounced. In some countries, government actions, unethical interventions from corporations, and the destructive actions of Mother Nature compound the difficulty of getting a "good title". In Haiti, for example, natural disasters, forced evacuations, and the corruption of dictatorships have made the prospect of figuring out who

\footnotetext{
${ }^{202} I d$.

${ }^{203} I d$.

${ }^{204} I d$.

${ }^{205}$ Frederick Reese, Land Registry: A Big Blockchain Use Case Explored, COINDESK (Apr. 19, 2017), https:/ /www.coindesk.com/blockchain-land-registry-solution-seeking-problem.

206 Katie Pyzyk, Vermont City to Use Blockchain for Land Registry, SMARTCiTiEsDive (Jan. 26, 2018), https://www.smartcitiesdive.com/news/vermont-city-to-use-blockchain-forland-registry $/ 515627 /$.

${ }^{207}$ Joanne Cleaver, Could Blockchain Technology Transform Home Buying in Cook County-and Beyond?, The Chicago TriB. (July 9, 2018), https://www.chicagotribune.com/ classified/realestate/ct-re-0715-blockchain-homebuying-20180628-story.html.
} 
actually owns the land one lives on impossible. ${ }^{208}$ Likewise, in the Gaza Strip, the current land speculation is bedeviled by conflicting claims by both the Israeli government and the Palestinian Authority, as well as the possible intervention of third parties. ${ }^{209}$ Other countries working on or preparing blockchain-based land and property registry processes include: Lantmäteriet land registry of Sweden, Ukraine, the Republic of Georgia, United Kingdom, the Indian State Andhra Pradesh, the Netherlands, Brazil and Singapore. ${ }^{210}$ Many believe that while blockchain is not going to 'replace government' concerning how land is registered and monitored, it will make governance of land registration the simplest and most corruption-resistant possible. ${ }^{211}$

\section{E-Government and Citizen Services}

Government responsibility-fiduciary, legal, and to the taxpayer-creates an incentive for ensuring accurate transfers of value between relevant stakeholders-within and between agencies, between the government and third parties, and between government and the citizenry. To facilitate faster and more efficient service, it would be beneficial for all governments to provide digital e-government services. Blockchain can provide a secure digital identity; it digitizes all new transaction data automatically and securely; and finally, it creates an interoperable platform across departments and agencies.

Estonia has led the way in using digital ledger technology (DLT) for citizen services since 2008, even before the Nakamoto whitepaper, and is home to the most famous blockchain-based digital government and eresidency program. ${ }^{212}$ This portal enables anyone to become an e-resident

208 Sam Cassatt, How Blockechain Can Help Haiti Recover, Consensys (Dec. 1, 2016), https://media.consensys.net/how-blockchain-can-help-haiti-recover-b1657b609ad1.

${ }^{209}$ Joseph J. Bambara \& Paul R. Allen, Blockchain: A Practical Guide to Developing Business, Law and Technology Solutions. MCGRAw HiLL EDUC. (2018), at 82.

${ }^{210}$ Nir Kshetro, Blockechain-Based Property Registries May Help Lift Poor People out of Poverty, GOV’T TECH. MAG. (June 28, 2018), http://www.govtech.com/computing/BlockchainBased-Property-Registries-May-Help-Lift-Poor-People-Out-of-Poverty.html.

${ }^{211}$ Reese, supra note 205.

${ }^{212}$ E-Residency 2.0 White Paper, E-ESTONIA (Dec. 18, 2018), https://e-estonia.com/wpcontent/uploads/faq-a4-v02-blockchain.pdf. 
of the country in 30-60 minutes and at a cost of 100 Euros. $^{213}$ Estonian e-residents can use the portal to create a digital identity, establish a business, setup banking relationships, and execute business documents. ${ }^{214}$ Through its E-Estonia initiative, ${ }^{215}$ the government facilitates voting, education, the justice system, legislation, and other services. ${ }^{216}$ Estonia's adoption of blockchain technology has created a successful test bed for generalized government applications for the blockchain such that it can be seen as a blueprint for success for potential blockchain applications elsewhere. $^{217}$

Not to be outdone, Dubai plans to become the first blockchainpowered government by $2020 .{ }^{218}$ Dubai will implement a solution to enable all government transactions on the blockchain as a part of the

${ }^{213}$ E-Residency 2.0 White Paper, supra note 212; see Nathan Heller, Estonia: the Digital Republic, THE NEW YORKER (Dec. 25, 2017), https://www.newyorker.com/magazine/ 2017/12/18/estonia-the-digital-republic (

Today, citizens can vote from their laptops and challenge parking tickets from home. They do so through the "once only" policy, which dictates that no single piece of information should be entered twice. Instead of having to "prepare" a loan application, applicants have their data-income, debt, savings - pulled from elsewhere in the system. There's nothing to fill out in doctors' waiting rooms, because physicians can access their patients' medical histories. Estonia's system is keyed to a chip-I.D. card that reduces typically onerous, integrative processes—such as doing taxes—-to quick work.).

${ }^{214}$ E-EsTONIA, https://e-estonia.com/ (last visited Jan. 20, 2019).

215 Id.

$216 I d$.

217 See Frequently Asked Questions, E-Estonia, https://e-estonia.com/wp-content/ uploads/faq-a4-v02-blockchain.pdf (last visited Jan. 20, 2019) (noting,

while it today takes on average about 7 months to discover the breach or misuse of an organization's data, the blockchain helps to discover such threats instantly. For example, cases like Snowden would never have happened if the NSA had been using blockchain technology like in Estonia. It is important to point out that although blockchain may not prevent the crime itself, it is $100 \%$ effective in detecting it.).

218 Surpara Dutt D' Cunha, Dubai Sets its Sights on Becoming the World's First BlockechainPowered Government, FORBES (Dec. 18, 2017), https://www.forbes.com/sites/suparnadutt /2017/12/18/dubai-sets-sights-on-becoming-the-worlds-first-blockchain-poweredgovernment/\#11a1a8de454b. 
'Smart Dubai' initiative. ${ }^{219}$ Dubai has emerged as a pioneer in the global space of blockchain application and has drastically reduced the economic costs associated with current bureaucratic processes. ${ }^{220}$ Visas, permits, licenses, and bill payments require 100 million documents annually, and the government believes that it can save $\$ 1.5$ billion through a paperless system as well as 25.1 million hours of productivity every year. ${ }^{221}$ Dubai also imports 200 billion in food from over 200 countries. $^{222}$ The municipality has launched a program to digitize its food safety protocols and will adapt blockchain as one of the technologies. ${ }^{223}$ It is a pioneering attempt to unwrap the regulatory challenges associated with widespread application of blockchain technology and as such it has already created a huge buzz in the industry with many companies wanting to capitalize on the new trade environment that comes with the deregulating effect of the blockchain. ${ }^{224}$

The UK government began exploring blockchain as early as 2015. ${ }^{225}$ As one of its members of Parliament has written,

[t]rust in public services grows as they become more transparent. Citizens should be able to own, see, hold, and control the use of their own data-the data that

219 Dubai Government to Embrace Blockchain Technology, KhALEEj Times (Oct. 6, 2016), https://www.khaleejtimes.com/nation/dubai/dubai-to-embrace-blockchain.

${ }^{220} \mathrm{Id}$.

${ }^{221}$ Dutt D’ Cunha, supra note 218.

222 Darin Detwiler, One Nation's Move to Increase Food Safety with Blockchain, BLOCKCHAIN UNLEASHED: IBM BlOCKCHAIN BlOG (Feb. 27, 2018), https://www.ibm.com /blogs/blockchain/2018/02/one-nations-move-to-increase-food-safety-withblockchain/.

${ }^{223}$ Sajila Saseendran, Dubai Launches High-tech Food Watch Programme, GulF NEws (Nov. 19, 2017), https://gulfnews.com/news/uae/health/dubai-launches-high-tech-foodwatch-programme-1.2126769; see also Judy Sebastian, Dubai is All Aboard with Blockchain and Big Data, FoOD QuAliTY AND SAFETY (Nov. 15, 2017),

https://www.foodqualityandsafety.com/article/dubai-aboard-blockchain-big-data/.

224 See generally Sanjaya Baru, Blockchain: The Next Innovation to Make Our Cities Smarter, FICCI (2018), https://www.pwc.in/assets/pdfs/publications/2018/blockchain-thenext-innovation-to-make-our-cities-smarter.pdf.

225 See generally Matthew Hancock, \&Ed Vaizey, Distributed Ledger Technology: Beyond Block Chain, UK GOV’T CHIEF SCIENTIFIC ADVISORS, https://assets.publishing.service.gov. uk/government/uploads/system/uploads/attachment_data/file/492972/gs-16-1-

distributed-ledger-technology.pdf. 
others are so keen to access, and that our security and wellbeing increasingly depends upon. In the past, the use of data was too often hidden behind organizations' firewalls, out of sight of the data's subjects. New technologies, however, such as blockchain, allow for more subject control, more transparency, and less need for centralized services. These new technologies provide greater technical resilience and security, too. ${ }^{226}$

\section{Identity Management}

Digital identity is both a use case for blockchain and the enabler that allows each of the other assets discussed for blockchain integration to exist.

Whether cryptocurrencies or cars, each asset needs to be rendered digitally to be transacted on a blockchain, and the owner or transactor also needs a digital identity to engage in those transactions. The magnitude of this challenge is recognized by public sector actors around the world-a world in which one-fifth of the world's population lives without a legal or officially recognized identity. ${ }^{227}$

The most developed government use of blockchain identity services is in Estonia with the e-Identity ID card, ${ }^{228}$ but trials are ongoing

\footnotetext{
226 Eddie Hughes, Embracing New Technologies to Drive Efficiency and Empower the Citizen, FREER UK, at 4 (July 2019), https://www.freeruk.com/wp-content/uploads/ 2018/07/Freer_Unlocking-Blockchain_approval.pdf.

227 Jason Killmeyer et al., Will Blockchain Transform the Public Sector, DeLoitTE, at 14, https://www2.deloitte.com/content/dam/insights/us/articles/4185_blockchainpublic-sector/DUP_will-blockchain-transform-public-sector.pdf (last visited Jan. 22, 2019); see also Allan Third et al., Government Services and Digital Identity, KNOWLEDGE MEDIA INST. OPEN U. (Aug. 1, 2018), at 5, https://www.eublockchainforum.eu/sites/default/ files/researchpaper/20180801_government_services_and_digital_identity.pdf?width=1 024 \&height $=800 \&$ iframe $=$ true.
}

While these methods could generally be implemented without the use of a blockchain, to do so would require identity systems to be hosted somewhere trustworthy, which would tend to lead to, if not require, centralization to some degree (under the assumption that most individuals would not choose to run their own hosting infrastructure).

228 E-Identity, E-ESTONIA, https://e-estonia.com/solutions/e-identity/id-card/ (last visited Jan. 23, 2019). 
or in development in Switzerland, ${ }^{229}$ Finland, ${ }^{230}$ Japan, ${ }^{231}$ the U.S., ${ }^{232}$ and $\mathrm{UNICEF}^{233}$ In most of these cases, the goal is to provide identity services to the initiating government's own citizens, but the Finnish trial is noteworthy as it uses blockchain to provide identification in the form of debit cards to refugees, a vulnerable group who typically cannot make use of traditional paper-based identities. ${ }^{234}$ The U.N. is also experimenting with new refugee identity stsems using blockchains in a collaboration with Accenture and Microsoft. ${ }^{235}$ The refugee case is an extreme example of a general identity problem which blockchains can address. Paper-based identity systems cannot be used across borders here because the government which would usually serve as a guarantor may be hostile, unreachable, or may not exist as a functioning entity. ${ }^{236}$ But even in less traumatic cases of international movement, the reliance on an individual's home government could be lessened by a secure digital identity service based on blockchain, reducing the number of parties involved in an interaction, and potentially increasing efficiency and trust.

5. Blockchain and the Sustainable Development Goals

In 2015, the United Nations announced the Sustainable Development Goals (SDGs), seventeen goals with 169 targets designed to "end poverty, protect the planet and ensure that all people enjoy peace and

${ }^{229}$ Paul Kohlhaas, Zug ID: Exploring the First Publicly Verified Blockchain Identity, UPORT (Dec. 6, 2017), https://medium.com/uport/zug-id-exploring-the-first-publicly-verifiedblockchain-identity-38bd0ee3702.

230 William Suberg, Findland Solves Refugee Identity with Blockchain Debit Cards, COINTELEGRAPH (Sept. 5, 2017), https://cointelegraph.com/news/finland-solvesrefugee-identity-with-blockchain-debit-cards.

231 Thad Reuter, Digital ID in Japan to be Powered by Blockchain, SECureID NEws (Oct. 30, 2017), https://www.secureidnews.com/news-item/digital-id-japan-powered-

blockchain/.

232 Theo Douglas, Illinois Announces Key Partnership in Birth Registry Blockchain Pilot, Gov’T TeCH. (Sept. 8, 2017), http://www.govtech.com/data/Illinois-Announces-KeyPartnership-in-Birth-Registry-Blockchain-Pilot.html.

233 Wayan Vota, Five Examples of United Nations Agencies Using Blockchain Technology, ICTwORKS (Mar. 8, 2018), https://www.ictworks.org/united-nations-agencies-usingblockchain-technology/\#.XBVzrfZKjUp.

${ }^{234}$ Suberg, supra note 230.

${ }^{235}$ Jeff John Roberts, Microsoft and Accenture Unveil Global ID Systems for Refugees, FORTUNE (June 19, 2017), http:// fortune.com/2017/06/19/id2020-blockchain-microsoft/.

$236 \mathrm{Id}$. 
prosperity" by 2030. ${ }^{237}$ The SDGs, adopted by 193 nations, require a partnership between the public sector and private enterprise. ${ }^{238}$

The U.N. has several projects related to blockchain and the SDGs. In 2017, fifteen U.N. agencies had blockchain initiatives and pilots ranging from alternate financing; managing the U.N. car fleet; e-trade for all, allowing people to start online businesses; and streamlining remittances. ${ }^{239}$ A recent report listed over one hundred potential use cases but found that blockchain has the most utility for SDGs related to decent work and economic growth; industry, innovation, and infrastructure; reduced inequalities; and peace, justice, and strong institutions. ${ }^{240}$

In the most well-known blockchain initiative, the U.N.'s World Food Programme (WFP) has used the Ethereum blockchain to help over 500,000 refugees in Jordan and Pakistan. ${ }^{241}$ The WFP uses blockchain to address the "no hunger" and "zero poverty" SDGs. ${ }^{242}$ The organization uses the technology for both digital identity through iris scans and the disbursement of $\$ 2$ billion and food to beneficiaries and plans to expand to Africa. ${ }^{243}$ Specifically, the technology has enabled female Syrian refugees to receive cash in supermarkets through iris scans because Jordanian police do not allow the delivery of cash into refugee camps

237 Sustainable Development Goals, U.N. Dev. Programme, http://www.undp.org/ content/undp/en/home/sustainable-development-goals.html (last visited Jan. 22, 2019). $238 \mathrm{Id}$.

${ }^{239}$ Heather Starkie, Usage of Blockchain in the UN System, UNITE (Aug. 2017), at 3-4, https://unite.un.org/sites/unite.un.org/files/session_3_b_blockchain_un_initiatives_fi nal.pdf.

240 Adam Fishman, SDG Knowledge Weekly: Blockchain, Mobile and Financial Technology Update, IISD (Aug. 20, 2018), http://sdg.iisd.org/commentary/policy-briefs/sdg-knowledgeweekly-blockchain-mobile-and-financial-technology-update/.

${ }^{241}$ Russ Juskalian, Inside the Jordan Refugee Camp That Runs On Blockchain, MIT TECH. REV. (Apr. 12, 2018), https://www.technologyreview.com/s/610806/inside-the-jordanrefugee-camp-that-runs-on-blockchain/.

242 Sustainable Development Goals, supra note 237.

243 Anna Baydakova, UN Food Program to Expand Blockchain Testing to African Supply Chain, COINDESK (Sept. 26, 2018), https://www.coindesk.com/un-food-program-to-expandblockchain-testing-to-african-supply-chain; Blockchain for Zero Hunger, WFP, https://innovation.wfp.org/project/building-blocks (last visited Jan. 22, 2019); Juskalian, supra note 241 (the author also attended a Humanitarian Blockchain Summit on Dec. 7, 2018 and has slides on file with more detailed information). 
and ATMs, and banks are not accessible. ${ }^{244}$ WFP reports that using blockchain for disbursements has eliminated ninety-eight percent of its transaction fees. ${ }^{245}$

The U.N. has also explored blockchain to monitor climate change reporting and impacts. ${ }^{246}$ The members of the Climate Change Coalition have pledged to consider the technology to assist with compliance with the Paris Accord; measurement and recording of interventions; building stakeholder capacity in developing countries; standardization of climate change governance; mitigation of fraudulent activity with DLT and climate change; and contribution to the achievement of the SDGs. ${ }^{247}$

The U.N. does not just use the technology, it has invested in it as well. $^{248}$ In fact, UNICEF has invested over \$11 million in blockchain startups looking to solve problems related to poor and vulnerable children. ${ }^{249}$ UNICEF's Innovation Team believes that blockchain can provide a new avenue to donate money, increase transparency, and reduce friction in transactions by leveraging tokenization. ${ }^{250}$ The UNICEF fund has sponsored hackathons to address the refugee crisis, ${ }^{251}$ explored the possibility of using passive distributed mining networks to create investment funding opportunities, ${ }^{252}$ looked at the use of Bitcoin's role in

\footnotetext{
244 Juskalian, supra note 241.

${ }^{245} \mathrm{Id}$.

246 UN Supports Blockchain Technology for Climate Action, U.N. (Jan. 22, 2018), https://unfccc.int/news/un-supports-blockchain-technology-for-climate-action.

24810 Great Examples of How the UN Is Using Blockchain Technology for Social Good, CRYPTOCOIN (Dec. 20, 2017) https://cryptocoin.news/news/10-great-examples-ofhow-the-un-is-using-blockchain-technology-for-social-good-4846/.

${ }^{249} I d$.

250 Blockchain, UNICEF, https://www.unicef.org/innovation/blockchain (last visited Jan. 22, 2019).

${ }^{251}$ UNICEFStories, Blockchain Hackathon Mexico: Tackling the Refugee Crisis, One Digital Leap at a Time, UNICEF (Oct. 19, 2018), http://unicefstories.org/2018/ 10/19/blockchain hackathonmx/.

${ }^{252}$ UNICEF Funding Opportunity for Blockchain Start-ups, UNICEF, http:/ / unicefstories.org /blockchaincall/ (last visited Jan. 22, 2019).
} 
sex trafficking, ${ }^{253}$ and sought research on smart contracts for multisignatory initiatives. ${ }^{254}$

\section{CORPORATE GOVERNANCE, COMPLIANCE, AND ENTERPRISE RISK MANAGEMENT}

Companies of all sizes have compliance and risk management obligations. Blockchain has the potential to aid - if not revolutionizecompliance because it can reduce delay, cut costs, avoid duplication, and discover errors or fraud early. Larger companies, their vendors, and business partners must contend with increased regulatory scrutiny, changing regulations from a number of jurisdictions, data protection obligations, and enhanced disclosure requirements. Accordingly, blockchain's immutability, tamper-resistance, and timestamping make it an ideal tool for compliance practitioners.

\section{A. Blockechain and Audit}

Auditors play a critical role in compliance because they ensure the accuracy of the company's books and records. ${ }^{255}$ Generally, external auditors focus on a company's financial reporting and financial risk and provide reports that shareholders and outsiders can rely upon. ${ }^{256} \mathrm{~A}$ company's internal auditor evaluates a company's risk management, internal controls, and governance on all areas of risk, not just financial risk. $^{257}$ Internal and external auditors work closely together, but internal auditors report to the board and senior management. ${ }^{258}$ Nonetheless, internal auditors must retain independence. ${ }^{259}$ Auditors play such an important role to shareholders and the larger public marketplace because

253 Brett Israel, In a Step Toward Fighting Human Trafficking, Sex Ads Are Linked to Bitcoin Data, Berkeley News (Aug. 16, 2017), https://news.berkeley.edu/2017/08/16/in-astep-toward-fighting-human-trafficking-sex-ads-are-linked-to-bitcoin-data/.

254 UNICEF Funding Opportunity for Blockechain Start-ups, supra note 252.

255 John Bendermacher, Global Perspectives and Insights: Internal Audit and External Audit, INST. INTERNAL AUDITORS, https://na.theiia.org/periodicals/Public\%20Documents/ GPI-Distinctive-Roles-in-Organizational-Governance.pdf (last visited Jan. 22, 2019).

$256 I d$.

257 See What Is Internal Audit?, Chartered InStitute of InTERnAL Auditors, https://www.iia.org.uk/about-us/what-is-internal-audit/ (last visited Jan. 22, 2019); Bendermacher, supra note 255.

258 Bendermacher, supra note 255.

${ }^{259} I d$. 
they provide assurances that a company's financial statements do not have material misstatements, and that internal controls over financial reporting are operating as they should. ${ }^{260}$

Because blocks are validated and recorded, companies could conceivably use the technology to provide proof that they have complied with various steps required by regulation. Internal and external auditors could thus track compliance, as could regulators. Additionally, blockchain allows for the tracking of goods and data in real time, which enables more timely and accurate analysis. For these reasons, the audit community does not see blockchain as a passing fad, but rather as a potential tool. ${ }^{21}$ While acknowledging the scalability issues with blockchain, the Chartered Professional Accountants of Canada (CPA Canada) and the American Institute of CPAs (AICPA) have advised their respective members to learn about the technology because it "has the potential to impact all recordkeeping processes, including the way transactions are initiated, processed, authorized, recorded, and reported. Changes in business models and business processes may impact backoffice activities such as financial reporting and tax preparation." ${ }^{262}$

In fact, in July 2018, KPMG, EY, PwC, and Deloitte, announced that they had joined a Taiwanese pilot program to test blockchain for fiscal audits. ${ }^{263}$ As Deloitte has observed, because the records are time stamped and can't be destroyed, companies could write transactions directly into a joint ledger, which could improve financial reporting and enhance internal controls. ${ }^{264}$

Blockchain also has the potential to automate certain audit transactions because it will reduce the need for an auditor to test them. ${ }^{265}$

${ }^{260} I d$.

${ }^{261}$ Blockchain Technology and its Potential Impact on the Audit and Assurance Profession, AICPA (2017), at https://www.aicpa.org/content/dam/aicpa/interestareas/frc/assuranceadvisoryservice s/downloadabledocuments/blockchain-technology-and-its-potential-impact-on-theaudit-and-assurance-profession.pdf.

$262 I d$.

263 See La Quercia, supra note 25.

264 Blockchain Technology-Creating a Decentralized Future, DeLoitTe (Feb. 22, 2017), https://www.iasplus.com/en-ca/cfos-corner/technology/a-decentralized-future.

265 Blockchain: How This Technology Could Impact the CFO, ERNST \& YOUNG (2017), at 4, https://www.ey.com/Publication/vwLUAssets/EY-blockchain-how-this-technology- 
As EY explains, this leaves the auditor available to "focus on confirming the validity of digital representation of physical assets and codification of contracts in conjunction with accounting standards rather than auditing transactions. This enables greater focus on more complex transactions and internal controls, fundamentally changing the scope and approach of an audit opinion." 266

Nonetheless, blockchain may have some limitations for auditors. As the AICPA and CPA Canada report notes, the chain could still have transactions that are "unauthorized, fraudulent or illegal; executed between related parties; linked to a side agreement that is 'off-chain'; or incorrectly classified in the financial statements."267 Auditors will thus have to understand the consensus protocol for the blockchain to ensure its reliability. ${ }^{268}$ On balance, however, these auditors appear cautiously optimistic that blockchain will reduce labor intensive manual data extraction and allow continuous auditing of routine procedures. ${ }^{269}$ Possible future roles for auditors include auditing smart contracts and oracles to ensure that they comport with the stated triggering events; providing independent assurance to consortium blockchains that the architecture meets stated robustness and stability requirements; and reporting on the effectiveness of controls of a permissioned blockchain. ${ }^{270}$ Ironically, although blockchain aims to eliminate the need for trusted intermediaries, trusted auditors will play a significant role in ensuring that companies and stakeholders trust the technology.

\section{B. Blockechain and Know Your Customer/ Anti-money Laundering Compliance}

KYC processes provide the backbone of financial institutions' anti-money laundering efforts and help to detect and prevent criminal behaviors. Dozens of countries besides the United States have these kinds of mandatory customer due diligence rules, which differ from jurisdiction

could-impact-the-cfo/\$FILE/EY-blockchain-how-this-technology-could-impact-thecfo.pdf.

${ }^{266} \mathrm{Id}$.

267 Blockchain Technology and its Potential Impact on the Audit and Assurance Profession, supra note 261 , at 10 .

${ }^{268} I d$.

${ }^{269} I d$.

${ }^{270} I d$. at 12 . 
to jurisdiction; thus, the verifications are not portable for clients. ${ }^{271}$ Despite the importance of the regulations, KYC at many financial institutions is an inefficient and tedious processes, rife with duplication of effort and risk of error, which is costly and could negatively impact the customer experience. According to a 2017 Thomson Reuters report, banks take an estimated 24-29 days to onboard a customer and twelve percent of customers had changed banks because of the onboarding process. ${ }^{272}$ Financial institutions with a turnover of over $\$ 10$ billion spent nearly $\$ 150$ million on average complying with KYC rules. ${ }^{273}$ The average amount spent for all institutions responding to the Thomson Reuters survey was $\$ 40$ million. ${ }^{274}$ Sales people around the world spend an average of twenty-seven percent of the workweek onboarding customers. ${ }^{275}$

The immutability and transparency of blockchain provides a streamlined way for financial institutions to gain swift and secure access to clean and updated customer data. This results in greater operational efficiency; increased trust between institutions; and reduction of laborintensive data gathering, processing time, and costs. For regulators, the use of blockchain provides a single source of customer data for better understanding and visibility of customer activity across financial institutions. From a customer standpoint, an institution's use of a blockchain-enabled KYC utility could reduce onboarding wait times and eliminate the need to repeatedly provide the same information to their financial services providers.

271 List of Approved KYC Rules, IRS, https://www.irs.gov/businesses/internationalbusinesses/list-of-approved-kyc-rules; see John Callahan, Know Your Customer (KYC) Will Be a Great Thing When it Works, FORBES (July 10, 2018), https:// www.forbes.com/sites/forbestechcouncil/2018/07/10/know-your-customer-kyc-willbe-a-great-thing-when-it-works/\#53b4cd6b8dbb (describing additional challenges with KYC compliance).

${ }^{272}$ KYC Compliance: The Rising Challenge for Financial Institutions, THOMSON REUTERS, at 6, 14, https://www.refinitiv.com/content/dam/gl/en/documents/reports/kyc-complia nce-the-rising-challenge-for-financial-institutions-special-report.pdf (last visited Jan. 22, 2019).

273 Id. at 4 .

${ }^{274} I d$. at 10 (see graph).

275 Stephen Wolf, GLEIF Identifies That Over Half of Salespeople in Banking Spend 27\% of Their Working Week Onboarding New Client Organizations, GLEIF (May 5, 2018), https://www.gleif.org/en/newsroom/blog/gleif-identifies-that-over-half-ofsalespeople-in-banking-spend-27-of-their-working-week-onboarding-new-clientorganizations. 
This past summer, thirty-nine financial firms partnered with blockchain consortium R3 and completed more than 300 transactions via R3's KYC application. ${ }^{276}$ R3's KYC project involved major financial and banking institutions worldwide such as Deutsche Bank, ING, the National Bank of Egypt, Raiffeisen Bank International, and others. ${ }^{277}$ It also involved regulators and central banks such as the Central Bank of Colombia, the Federal Reserve Bank of Boston, and the Financial Superintendence of Colombia. ${ }^{278}$ The transactions were conducted across eight time zones in nineteen countries, wherein banks could request access to customer KYC data, and clients could grant or revoke access. ${ }^{279}$ "David E. Rutter, CEO of R3, said the goal of the Corda-based KYC application is to speed up the usually 'slow and time-consuming' process of verifying customer identity for financial transactions, also noting an increasing demand for blockchain-based KYC solutions."'280

\section{Blockechain and Cybersecurity}

Seven million data records were breached in 2017, most through human error, but many through malicious attack. ${ }^{281}$ In 2018, "[a]t least 35 states, D.C. and Puerto Rico introduced . . . 265 bills . . . related to cybersecurity." 282 Depending on company size and industry, companies must also contend with the NIST Cybersecurity Framework, ${ }^{283}$ the

27639 Firms Complete Global Trial of KYC on Corda Blockchain Platforms, R3 (June 28, 2018), https://www.r3.com/news/39-firms-complete-global-trial-of-kyc-on-corda-blockchain -platform/.

277 Id.

${ }^{278} I d$.

${ }^{279} I d$.

${ }^{280}$ Helen Partz, Banks and Regulators Complete KYC App Test on R3 Blockchain Platform, COINTELEGRAPH (June 30, 2018), https://cointelegraph.com/news/banks-andregulators-complete-kyc-app-test-on-r3-blockchain-platform.

281 Gemelato, 2017 Data Breach Level Index: Full Year Results Are In..., Gemelato (Apr. 13, 2018), https://blog.gemalto.com/security/2018/04/13/data-breach-stats-for-2017-fullyear-results-are-in/.

${ }^{282}$ Cybersecurity Legislation 2018, NATIONAL CONFERENCE OF STATE LEGiSLATURES (Nov. 6, 2018), http://www.ncsl.org/research/telecommunications-and-informationtechnology/cybersecurity-legislation-2018.aspx.

283 Framework for Improving Critical Infrastructure Cybersecurity, NIST (Apr. 16, 2018), https://nvlpubs.nist.gov/nistpubs/CSWP/NIST.CSWP.04162018.pdf 
Healthcare Information Portability and Accountability Act, ${ }^{284}$ the Internet of Medical Things Resilience Partnership Act, ${ }^{285}$ the Medical Device Cybersecurity Act of 2017, ${ }^{286}$ FINRA rules, ${ }^{287} 23$ NYCRR 500 cybersecurity regulation issued by the Department of Financial Services, ${ }^{288}$ SEC guidance, ${ }^{289}$ PCI DSS, ${ }^{290}$ and other regulations. Internationally, covered firms must comply with the Cybersecurity Law of the People's Republic of China, ${ }^{291}$ the EU's General Data Protection Act, ${ }^{292}$ and dozens more.

Blockchain provides at least four benefits related to cybersecurity. First, the lack of a central point of contact or locus of information-

284 See generally Summary of the HIPAA Security Rule, U.S. DeP’ HeALTH \& Hum. SERvs., https://www.hhs.gov/hipaa/for-professionals/security/laws-regulations/index.html (last visited Jan. 22, 2019).

285 See generally H.R. 3985, 115th Cong. (2017).

286 See generally S. 1656, 115th Cong. (2017).

287 See generally Cybersecurity, FinANCIAL INDUSTRY REgUlatory Authority, http:// www.finra.org/industry/cybersecurity (last visited Jan. 22, 2019).

288 See generally Cybersecurity Requirements for Financial Service Companies, 23 NYCRR 500, New York State, https://www.dfs.ny.gov/legal/regulations/adoptions/dfsrf500txt.pdf.

289 See generally SEC Announces Enforcement Initiatives to Combat Cyber-Based Threats and Protect Retail Investors, SEC. \& ExCH. COMM’N (Sept. 25, 2017), https://www.sec. gov/news/press-release/2017-176; 17 C.F.R. SS 229 \& 249.

290 See generally PCI Security, PCI SEC. STANDARDS COUnCIL, https:// www.pcisecuritystandards.org/pci_security/ (last visited Jan. 22, 2019).

291 See generally Overview of China's Cybersecurity Law, KPMG (Feb. 2017), at 7-10, https://assets.kpmg.com/content/dam/kpmg/cn/pdf/en/2017/02/overview-of-

cybersecurity-law.pdf.

292 See generally Data Protection, EuR. COMM'N, https://ec.europa.eu/info/law/lawtopic/data-protection_en (last visited Jan. 22, 2019); Josh Eichorn, Life Under \#GDPR and What it Means for Cybersecurity, InFOSECURITY (Apr. 25, 2018), https://www.infosecurity-magazine.com/opinions/life-gdpr-cybersecurity/ (Many have raised concerns about blockchain's incompatibility with the GDPR because the law includes the right to be forgotten, and blockchains generally do facilitate easy deletion or changes of data. In November 2018, the French data protection authority, CNIL, issued guidance on compliance with the GDPR. The CNIL found that blockchain can in fact enhance compliance with GDPR but also indicated that it will work with other EU authorities to develop a harmonized approach to compliance.); Blockchain and the GDPR: Solutions for a Responsible Use of the Blockchain in the Context of Personal Data, CNIL (Nov. 6, 2018), https://www.cnil.fr/en/blockchain-and-gdpr-solutions-responsible-use-block chain-context-personal-data. 
decentralization-means that if one node goes down, the data is not lost. Additionally, a company does not need to engage a third party to process or verify transactions. Second, the encryption and validation process means provides a mechanism to ensure that the data has not been altered, even if it is stored in the cloud. Third, although it is not impossible to hack, blockchain is tamper resistant and one would have to hack most of the nodes at the same time. Further, any attempts to alter or remove data would likely be noticed by other nodes. Finally, companies worried about intrusions from outsiders can use private blockchains.

More specifically, blockchain can improve data integrity, resiliency, and transparency. One potential use case involves IoT or the Internet of Things. Smart devices benefit companies but pose security challenges. Blockchain's tamper resistance makes it a logical tool to safeguard digital assets and could strengthen authentication. ${ }^{293}$ The UK government has provided a grant for the Isle of Man to test the technology to see if it can prevent hacking. ${ }^{294}$ Blockchain can also provide more secure messaging. Companies that allow employees to use chat services boasting end-to-end encryption are still vulnerable to hacking. Blockchain could add an extra layer of protection. ${ }^{295}$ The technology could also change or eliminate the need to use the cryptography known as Public Key Infrastructure (PKI), which secures emails and other forms of communication. ${ }^{296}$ PKIs are vulnerable to hackers spoofing identities. ${ }^{297}$ Putting keys on the blockchain would make it easier to verify identities. ${ }^{298}$ Blockchain companies are also using the technology to prevent distributed denial of

293 Doug Drinkwater, 6 Use Cases for Blockchain in Security, COMPUTERWORLD (Feb. 6, 2018), https://www.computerworld.com.au/article/633059/6-use-cases-blockchainsecurity/.

${ }^{294}$ Rene Millman, Isle of Man Tests Blockchain to Secure IoT Devices, InTERNET OF Bus. (Aug. 9, 2016), https://internetofbusiness.com/isle-man-tests-blockchain-secure-iot/.

295 Omri Barzilay, 3 Ways Blockchain Is Revolutionizing Cybersecurity, FORBES (Aug, 21, 2017), https://www.forbes.com/sites/omribarzilay/2017/08/21/3-ways-blockchain-isrevolutionizing-cybersecurity/\#af4887a23349; Jayanand Sagar, Obsidian Gains the Attention of Mainstream Investors, News BTC (Aug. 14, 2017), https:/ /www.newsbtc.com/ 2017/08/14/obsidian-gains-attention-mainstream-investors-focuses-strategicpartnerships/.

${ }^{296}$ Drinkwater, supra note 293.

297 Id.

298 Id. 
service attacks and removing the single point of contact for domain name systems, thereby making shutdowns of websites less likely. ${ }^{299}$

Blockchain's utility for cybersecurity is not theoretical. Lockheed Martin, America's largest defense contractor, has announced that it is exploring blockchain to combat cyberthreats. ${ }^{300}$ Lockheed retained the same company, Guardtime, that secures Estonia's one million health records. ${ }^{301}$ Similarly, Ukraine's defense industry has also embraced blockchain to allow passwordless login for employees. ${ }^{302}$ In November 2018, the U.S. Department of Defense sent out a request for information, acknowledging that " $[\mathrm{t}]$ hese technologies have dramatic implications for the security and resilience of critical data storage and computation tasks, including for the Department of Defense (DoD)." "303 Although the DoD indicated that the use cases are unclear, it is a promising sign that the DOD has joined other government agencies looking at blockchain for cybersecurity. ${ }^{304}$ Significantly, the DoD has expressed interest in permissionless blockchains that do not require any monetary incentives, whether cryptocurrency or fiat. ${ }^{305}$ The Defense Advanced Research Project Agency has explored a number of blockchain initiatives for secure messaging, supply chain management, and protection of hardware. ${ }^{306}$

\section{Blockechain and Corporate Governance}

Blockchain will transform corporate governance, the process by which companies are controlled and directed. Boards of directors

${ }^{299} I d$.

300 Lockheed Martin Partners with Guardtime Federal for Innovative Cyber Technology, LOCKHEED MARTIN (July 9, 2018), https://news.lockheedmartin.com/2018-07-09-LockheedMartin-Partners-with-Guardtime-Federal-for-Innovative-Cyber-Technology.

${ }^{301}$ Lockheed Martin Partners with Guardtime Federal for Innovative Cyber Technology, supra note 300; Barzilay, supra note 295.

302 Barzilay, supra note 295.

303 RFI: Applications and Barriers to Consensus Protocols (ABC), Fed. Bus. Opportunities, https:/ /www.fbo.gov/index?s $=$ opportunity\&mode $=$ form\&id=0de0f789b3f1782b6030 $\mathrm{a} 044 \mathrm{~b} 55 \mathrm{fb} 006 \& \mathrm{tab}=\mathrm{core} \& \_\mathrm{cview}=0$.

304 Id.

305 Mark Emem, US Military's DARPA Program Hops on the Blockchain Not Bitcoin' Bandwagon, CCN (Nov. 24, 2018), https://www.ccn.com/us-militarys-darpa-programhops-on-the-blockchain-not-bitcoin-bandwagon/.

306 David Hamilton, DARPA Blockchain Programs, CoIN CenT. (Oct. 1, 2018), https://coincentral.com/darpa-blockchain-programs/. 
typically have oversight for this corporate governance, and shareholders elect board members and hold them accountable. ${ }^{307}$ Both boards and shareholders could benefit from the technology. For example, companies using permissioned blockchain and smart contracts could automatically update records when shares are issued, sold, or transferred, which will provide shareholders, regulators, and other investors with real-time access to information. This would force transparency so that the company's debt and equity holdings would be clear to all, and insider trading and other inappropriate actions would come to light immediately. ${ }^{308}$ As an added benefit, investors would no longer have to wait for certain SEC filings because the disclosures would always be available. ${ }^{309}$ Further, companies of all sizes could benefit from more accurate capitalization tables. ${ }^{310}$ Firms could also develop smart contracts for employee stock options or warrants held by other investors. ${ }^{311}$ Finally, smart contracts could ensure compliance with private placement rules by issuing shares to digital wallets of accredited investors. ${ }^{312}$

Additionally, blockchain could completely change proxy voting by alleviating problems of inexact voter lists and tabulation errors because all users would have access to the ledgers. ${ }^{313}$ As Fiammetta S. Piazza explains,

307 Corporate Governance Defined: Not So Easily, CORP. GOVERNANCE, https://www.corpgov.net/library/corporate-governance-defined/ (last visited Jan. 22, 2019).

308 David Yermack, Corporate Governance and Blockchains, HARV. L. SCH. F. CORP. GOVERNANCE \& Fin. REG. (Jan. 6, 2016), https://corpgovlaw.harvard.edu/ 2016/01/06/corporate-governance-and-blockchains/.

309 See Fiammetta S. Piazza, Bitcoin and the Blockchain as Possible Corporate Governance Tools: Strengths and Weaknesses, PENN ST. J. L. \& INT’L AFF. 261, 290 (2017).

310 See, e.g., Andrea Tinianow, Delaware Blockchain Initiative: Transforming the Foundational Infrastructure of Corporate Finance, HARV. L. SCH. F. CORP. GOVERNANCE \& FIN. REG. (Mar. 16, 2016), https://corpgov.law.harvard.edu/2017/03/16/delaware-blockchain-initiative -transforming-the-foundational-infrastructure-of-corporate-finance/; Will Nigri, Remaining Private on the Blockchain-Security Tokens/Tokenizing Your Cap Table for Private Companies, MEDIUM (Sept. 17, 2018), https://medium.com/front-seat-capital/ remaining-private-on-the-blockchain-security-tokens-tokenizing-your-cap-table-forprivate-fb2fecbd0e24.

311 Yermack, supra note 307.

312 G. Thomas Stromberg et al., Are Headwinds Hampering Delaware's Blockchain Initiative?, LEXOLOGY (Mar. 23, 2018), https://www.lexology.com/library/detail.aspx?g $=\mathrm{ca} 0 \mathrm{~d} 4578-3005-4 \mathrm{c} 08-9969-\mathrm{b} 86 \mathrm{a} 8425 \mathrm{ae} 4 \mathrm{a}$.

313 Piazza, supra note 309, at 293. 
voting via blockchain would work "by allocating eligible voters tokens (also called 'vote coins') in a number that represents their voting power. Voters would then transmit to addresses on the blockchain their vote, which would then be registered on the ledger."314 Proxy voting by blockchain is already on the horizon. In May 2018, Broadridge, one of the world's largest providers of investor-relations services, obtained a patent to add more transparency and efficiency to the proxy voting process. ${ }^{315}$

States and companies could also use the technology for renewals of Uniform Commercial Code (UCC) financing statements. States require each company to register assets to conform with the UCC. ${ }^{316}$ Instead of going to each secretary of state, managers and creditors could theoretically go to a blockchain where all of the relevant information would be digitized. ${ }^{317}$

Highlighting blockchain's viability, Delaware is implementing a blockchain system to track precise stock ownership through a single ledger in real time. ${ }^{318}$ In July 2017, the state approved stock trading via the blockchain by passing a bill that was drafted to address some of the gaps in the legal and legislative framework to regulate blockchain technology. ${ }^{319}$ It is a pioneering attempt to unwrap the regulatory challenges associated with widespread application of blockchain technology. ${ }^{320}$ In July 2018, the state announced a partnership with IBM to automate business processes and to allow regulators and investors to have real time access to stocks and

${ }^{314} I d$

315 Broadridge Awarded Blockchain Patent for Proxy Voting, FineXTRA (May 11, 2018), https://www.finextra.com/newsarticle/32090/broadridge-awarded-blockchain-patentfor-proxy-voting.

316 See, e.g., Daniel W. Lias, What You Need to Know About Common Uniform Commercial Code (UCC) Forms, WOLTERS KLUWER (June 7, 2018), https://ct.wolterskluwer.com/ resource-center/articles/what-you-need-know-about-common-uniform-commercialcode-ucc-forms.

317 Lewis Cohen \& Soraya Ghebleh, On Governance: How Will Blockchain Technology Change Organizational Governance?, THE CONF. BOARD (Mar. 21, 2018), https://www.conferenceboard.org/blog/postdetail.cfm?post $=6734$.

318 David Dinkins, Delaware Approves Tracking of Stock Ownership on Blockchain, Major Effects, COINTELEGRAPH (Sep. 20, 2017), https:// cointelegraph.com/news/delaware-approvestracking-of-stock-ownership-on-blockchain-majoreffects.

${ }^{319} I d$.

${ }^{320} I d$. 
assets. $^{321}$ Because more than sixty-six percent of the Fortune 500 have incorporated in Delaware, ${ }^{322}$ any pilot programs that it approves or denies through the Delaware Blockchain Initiative will likely have a ripple effect for other states and impact a large number of shareholders.

Blockchain will streamline processes, improve accuracy, and save money in corporate governance, but it could also help investors and companies deal with a multitude of nonfinancial disclosures. Although shareholders, particularly institutional shareholders, clearly value wealth maximization, more are also pressing companies to provide data on environmental, social, and governance factors (ESG). As with other data, access to reliable, real-time data will be critical for investors, especially when the impact to the bottom line is less obvious.

In January 2018, BlackRock, which holds over $\$ 6.3$ trillion in assets under management, ${ }^{323}$ informed companies that it would focus on sustainability, stating:

Your company's strategy must articulate a path to achieve financial performance. To sustain that performance, however, you must also understand the societal impact of your business as well as the ways that broad, structural trends-from slow wage growth to rising automation to climate change_-affect your potential for growth . . . a company's ability to manage environmental, social, and governance matters demonstrates the leadership and good governance that is so essential to sustainable growth, which is why we are increasingly integrating these issues into our investment process. Companies must ask themselves: What role do we play in the community? ${ }^{324}$

BlackRock has repeatedly reiterated its focus on investing for positive social and environmental impact as well as financial results because

\footnotetext{
${ }^{321}$ Lucas Mearian, Delaware to Test Blockchain-based Business Filing System, COMPUTERWORLD (July 12, 2018), 2 https://www.computerworld.com/article/ 3289484/blockchain/delaware-to-test-blockchain-based-business-filing-system.html.

322 Id.

${ }^{323}$ Christine Williamson, BlackRock, AUM Slips in Second Quarter, but Up for Year, PENSIONS \& INVS. (July 16, 2018) https://www.pionline.com/article/20180716/ONLINE/ 180719909/blackrock-aum-slips-in-quarter-but-up-for-year.

324 Larry Fink, A Sense of Purpose, BLACKRock, https://www.blackrock.com/ $\mathrm{hk} / \mathrm{en} /$ insights/larry-fink-ceo-letter (last visited Jan. 23, 2019).
} 
investors, particularly wealth managers and millennials, are asking more questions about more sustainable options. ${ }^{325}$ This is not a fluke. As of year-end 2017, one in four dollars under professional management in the United States_over \$12 trillion-was invested according to socially responsible investment strategies (SRI). ${ }^{326}$ In 2015, the number was one in five dollars. ${ }^{327}$ BlackRock's stated commitment to hold companies accountable for ESG factors and to promote such investments to its own clients ${ }^{328}$ may increase the SRI spending.

ESG factors also matter to proxy advisory firms. Institutional Shareholder Services (ISS), the world's largest proxy advisory firm, ${ }^{329}$ recently launched an Environmental and Social (E\&S) Quality Score Disclosure and Transparency Signal scoring tool that provides a new metric for institutional investors to fully evaluate the ESG risk of their portfolio companies. ${ }^{330}$ Proxy advisory firms play a key role in corporate governance because they advise institutional investors on how to vote on shareholder and management proposals. ${ }^{331}$ ISS developed the tool because institutional investors increasingly consider ESG when investing and voting their shares. ${ }^{332}$ ISS's key factors include human rights, management policies, systems and disclosure, consultation and engagement, ethical sourcing, and supply chain standards. ${ }^{333}$ ISS gathers

325 Julia Horowitz, BlackRock is Getting Ready for Millennials, CNN (Dec. 4, 2018), https://www.cnn.com/2018/12/04/investing/blackrock-millennial-push/index.html; https://www.blackrock.com/americas-offshore/insights/blackrock-investmentinstitute/sustainability-the-future-of-investing.

326 SRI Basics, USSIF, https://www.ussif.org/sribasics (last visited Jan. 22, 2019).

327 Id.

328 See generally Sustainable Investing Is Simply Smart Investing, BLACKRocK, https://www.blackrock.com/investing/investment-ideas/sustainable-investing (last visited Jan. 22, 2019).

329 What Sets ISS Apart, INSTIT. S'HOLDER SERVS., https://www.issgovernance.com/ about/about-iss/ (last visited Jan. 22, 2019).

330 Environmental \& Social Disclosure QualityScore FAQ, INSTIT. S'HOLDER SERVS. (Oct. 2018), https://www.issgovernance.com/file/faq/Environmental-Social-QualityScoreFAQ.pdf.

331 See Proxy Advisory Firms, CTR ExEC. COMP., http://www.execcomp.org/ Issues/Issue/proxy-advisory-firms (noting problems including conflict of interests and lack of independence).

332 Environmental \& Social Disclosure QualityScore FAQ, supra note 330.

333 Id. 
data from, among other places, company corporate social responsibility or sustainability reports, the Global Reporting Initiative (GRI), and the Sustainability Accounting Standards Board (SASB) standards, discussed in Part IV of this Article. ${ }^{334}$ ISS cited the BlackRock 2018 voting guidelines as validation that investors seek this information. ${ }^{335}$ Significantly, ISS has stated that the E\&S scores will appear alongside the Governance Quality Score on the ISS Benchmark Proxy Analysis. ${ }^{336}$

Likewise, dozens of stock exchanges encourage ESG investment and disclosure. ${ }^{337}$ In 2009, the United Nations launched the Sustainable Stock Exchange Initiative (SSE) to "build the capacity of stock exchanges and securities market regulators to promote responsible investment in sustainable development and advance corporate performance on environmental, social and governance issues." 338 As of March 2019, the SSE has eighty-five partner exchanges including the New York Stock Exchange and NASDAQ in the United States. ${ }^{339}$ NASDAQ's Nordic exchanges launched an ESG portal in December 2018 to support sustainable investment and provide standardized ESG data. ${ }^{340}$ Thirty-nine SSE partner exchanges have voluntary disclosures and sixteen require them. ${ }^{341}$ The SSE works with securities regulators worldwide because sustainability issues can have a material impact on financial risk. ${ }^{342}$

\footnotetext{
334 Id. at 2.

$335 \mathrm{Id}$.

336 Id. at 8 .

337 List of Partner Exchanges, Suitable STOCK Exchs. Initiative (2017), http://www. sseinitiative.org/sse-partner-exchanges/list-of-partner-exchanges/; Statement in support of the SSE, N.Y. STOCK ExCH., https://www.nyse.com/sustainability/SSE.(last visited March 17, 2019).

338 About the SSE, Suitable STOck Exchs. Initiative (2017), http://www. sseinitiative.org/about/about-the-sse/.

339 List of Partner Exchanges, supra note 337.

340 Nasdaq Nordic Launches ESG Data Portal to Support Sustainable Investments, NASDAQ (Dec. 17, 2018).

341 Statement made at the UN Forum on Business and Human Rights, (Nov. 28, 2018) (Video not yet available.).

342 See Securities Regulators and Sustainable Development, Suitable STOck ExchS. IniTiATIVE (2017), http://www.sseinitiative.org/securities-regulators/.
} 
SSEs base their priorities on the UN's SDGs. Companies have good reason to get involved with the SDGs because an estimated $\$ 12$ trillion in investment opportunity is available for those that work on the various projects related to education, housing, infrastructure, health, and technology, among others. ${ }^{343}$ According to a 2018 report on the state of sustainable business, seventy-one percent of CEOs surveyed indicated that they use the SDGs to develop their sustainability strategies, with the most concentrated focus related to climate change; gender equality; decent work and economic growth; good health and well-being; and responsible consumption and production. ${ }^{344}$

Both investors and SSEs want to avoid the phenomenon of "garbage in and garbage out" and demand legitimate, verifiable data. ${ }^{345}$ Data on a blockchain can help by allowing consumers, producers, market participants, members in a supply chain, and governments to add and verify timestamped information without having to rely on self-serving corporate social responsibility reports touting their ESG achievements. Some argue that tokens can provide incentives for stakeholders to verify ESG data and to reward companies for improving their ESG footprints. ${ }^{346}$ However, companies would likely have to make these blockchains public and this could raise the environmental issues raised earlier with the proof of work consensus mechanisms. Proof of Authority mechanisms may make more sense, unless companies develop incentives for more energy efficient validation methods. ${ }^{347}$

Investors ask about ESG as one data point in their investment decision-making process, but some governments and civil society

\footnotetext{
343 See Rob van Tulder \& Jan Anton van Zanten, Major Companies Really Become Committed to Sustainable Development? FORBES (Sept. 17, 2018), https://www.forbes.com/sites/ rsmdiscovery/2018/09/17/can-the-worlds-major-companies-really-becomecommitted-to-sustainable-development/\#67360a115ef3.

344 The State of Sustainable Businesses 2018: Resulsts of the 10th Annual Survey of Sustainable Business Leaders, BSR (2018), at 24-25, https://www.bsr.org/reports/BSR_Globescan_ State_of_Sustainable_Business_2018.pdf.

345 Securities Regulators and Sustainable Development, supra note 342.

346 Russ Stoddard, How the Blockchain Could Transform Sustainability Reporting, GREENBIZ (Apr. 24, 2018), https://www.greenbiz.com/article/how-blockchain-could-transformsustainability-reporting.

${ }^{347}$ Heather Clancy, The Blockchain Isn't Doomed to Become an Energy Hog, GrEENBIZ (Feb. 8, 2018), https://www.greenbiz.com/article/blockchain-isnt-doomed-become-energyhog.
} 
organizations either mandate or strongly encourage disclosure. In Part IV, we will discuss the disclosure of human rights impact and how companies are using blockchain.

\section{BLOCKCHAIN AND HUMAN RIGHTS DISCLOSURES}

One of the more promising uses of blockchain eliminates barriers to transparency in the human rights arena, thereby satisfying various mandatory disclosure regimes and shareholder requests. We discuss some of the disclosure regimes below.

\section{A. Voluntary Corporate Social Responsibility Disclosures}

1. OECD Guidelines for Multinational Enterprises

According to the Organization for Economic Cooperation and Development (OECD), responsible business conduct requires companies to prevent risks and address the negative impacts when they occur, particularly in foreign jurisdictions. ${ }^{348}$ To aid its member states, the OECD established Guidelines for Multinational Enterprises (OECD Guidelines) in 1976. ${ }^{349}$ The nonbinding OECD Guidelines have a significant influence on member states' decisions to regulate business conduct, particularly in the areas of human rights, the environment, bribery, fair labor, consumer impact, and corporate governance. ${ }^{350}$ The OECD Guidelines cover all types of business relationships including suppliers, franchisees, licensees, joint ventures, investors, clients, contractors, customers, consultants, advisors, or any state or non-state actor linked to the products or services that the business provides. ${ }^{351}$ Because they helped develop them, most countries with ESG reporting requirements allow the use of the OECD Guidelines as an acceptable due diligence platform. ${ }^{352}$ The OECD has also developed Guidelines for Responsible Supply Chains of Minerals from Conflict-Affected and High-Risk Areas. ${ }^{353}$ All 35 OECD Members, and 8 non-Members (Argentina, Brazil, Colombia, Costa Rica, Lithuania,

348 OECD Due Diligence Guidance for Responsible Supply Chains of Minerals from Conflict-Affected and High-Risk. Areas, OECD, https://www.oecd.org/fr/daf/inv/mne/mining.htm.

349 OECD guidelines for multinational enterprises, (2011), http://mneguidelines.oecd.org/guidelines/.

${ }^{350} \mathrm{Id}$.

${ }^{351} I d$.

$352 I d$.

353 OECD Due Diligence Guidance for Responsible Supply Chains of Minerals from Conflict-Affected and High-Risk Areas, OECD, https://www.oecd.org/fr/daf/inv/mne/mining.htm. 
Morocco, Peru, and Romania) adhere to the OECD recommendation on mineral supply chains. ${ }^{354}$

In September 2018, the OECD held the largest intergovernmental policy forum on blockchain where over 1,110 attendees discussed the technology's potential impact on privacy and cybersecurity, sustainability, and governance. ${ }^{355}$ The OECD has been and will continue to be a strong proponent for blockchain research. ${ }^{356}$ Accordingly, the technology will be a natural fit for gathering and reporting data within the OECD Guidelines and those disclosure regimes that follow them.

\section{Global Reporting Initiative}

In 1997, the Coalition for Environmentally Responsible Economics and the United Nations Environmental Program launched the most comprehensive objective sustainability framework to report on ESG factors. ${ }^{357}$ The GRI requires member companies to examine operational, governance, human rights, labor, environmental, property, consumer, community involvement, and development practices. ${ }^{358}$ GRI also partners with the OECD, the U.N. Global Compact, and the International Standards Organization (ISO). ${ }^{359}$ GRI claims that of the world's largest 250 corporations, ninety-three percent report on their sustainability

\footnotetext{
${ }^{354} I d$.

355 See OECD Blockchain Policy Forum, OECD (Sept. 4, 2018), http://www.oecd.org/ corporate/oecd-blockchain-policy-forum-2018.htm.

356 See Greg Medcraft, The OECD and the Blockchain Revolution, OECD FRIENDS OF GOING Digital MeETing, PARIS (Mar. 29, 2018), https://www.oecd.org/parliamentarians/ meetings/meeting-on-the-road-london-april-2018/The-OECD-and-the-Blockchain-

Revolution-Presentation-by-Greg-Medcraft-delivered-on-29-March-2018.pdf; Blockchain and Competition Policy, OECD, http://www.oecd.org/competition/blockchain-andcompetition-policy.htm; High-Level Panel: Blockchain for Better Policies, OECD (Sept. 4, 2018), http://www.oecd.org/about/secretary-general/high-level-panel-blockchain-forbetter-policies-paris-september-2018.htm.

357 GRIs History, GLOB.REPORTING InITIATIVE, available at https://www. globalreporting.org/information/about-gri/gri-history/Pages/GRIs history.aspx (last visited Aug 7, 2018).

358 Id.

359 GRI and Sustainability Reporting, GLOB. RePORTING InITIATIVE, https://www. globalreporting.org/information/sustainability-reporting/Pages/gri-standards.aspx (last visited Aug 7, 2018).
} 
performance, and eighty-two percent use the GRI standards. ${ }^{360}$ Thirtyfive countries have used the GRI standards to develop their own sustainability reporting requirements. ${ }^{361}$ Companies that implement the SDGs also use GRI for sustainable decision-making and standardized reporting. ${ }^{362}$ In July 2018, GRI announced that it will begin a two-year program to explore how blockchain and other digital technologies can enhance sustainability reporting while still maintaining security concerns. $^{363}$

\section{U.N. Global Compact}

The U.N. Global Compact (the "Compact") is the world's largest corporate sustainability initiative. ${ }^{364}$ The Compact supports companies that do business responsibly in accordance with ten specific principles on human rights, labor, the environment, anti-corruption, and companies that focus on advancing broader societal goals, such as the SDGs. ${ }^{365}$ As of December 2018, the Compact had 12,000 signatories in over 160 countries, including 9,000 companies and 3,000 nonbusiness participants. $^{366}$ As of March 2019, approximately 549 of the participants were U.S. based. ${ }^{367}$ Signatories must complete a Communication on Progress in their annual reports or their separate sustainability reports and are subject to expulsion if they fail to do so. ${ }^{368}$ Although the Compact has

360 Jose Luis Blasco et al., The KPMG Survey of Corporate Responsibility Reporting 2017, THE ROAD AHEAD: THE KPMG SuRVEY OF CORP. ReSP. REPORTING 2017, https://home. kpmg.com/content/dam/kpmg/campaigns/csr/pdf/CSR_Reporting_2017.pdf.

${ }^{361} I d$.

362 GRI and the SDGS, GLOB. REPORTING INITIATIVE, https://www.globalreporting. org/information/SDGs/Pages/GRI-and-SDGs.aspx.

363 The Future is Digital: Get Started with GRI's Digital Reporting Tool Now!, GLOB. REPORTING INITIATIVE, https://www.globalreporting.org/information/news-and-press-center/ Pages/gri-digital-reporting-tool-launch-july-2018.aspx.

364 U.N. GLOB. COMPACT, https://www.unglobalcompact.org/what-is-gc (last visited Aug. 7, 2018).

365 About the Sustainable Development Goals, U.N., https://www.un.org/sustainable development/sustainable-development-goals/ (last visited Aug. 7, 2018).

366 U.N. GLOB. COMPACT, supra note 364.

367 Explore Our Participants, U.N. GLOB. COMPACT, https://www.unglobalcomp act.org/interactive (last visited Aug. 7, 2018).

368 Create and Submit Your CoP, U.N. GLOB. COMPACT, https://www.unglobalcompact .org/participation/report/cop/create-and-submit (last visited Aug. 7, 2018). 
no enforcement mechanism, it does consider itself to be a mandatory disclosure framework. ${ }^{369}$ In July 2018, the Compact held a webinar on how to use blockchain for promoting decent working conditions in global supply chains. ${ }^{370}$ The session featured some of the largest companies in the world, including Nestle, Accenture, and Unilever. ${ }^{371}$

\section{ISO 26000:2010}

Some companies that rely on the OECD Guidelines also use ISO 26000:2010 to assist in ascertaining their social responsibility because the standards complement each other. ${ }^{372}$ ISO 26000:2010 provides guidance on organizational governance, human rights, labor practices, the environment, fair operating practices, consumer issues, and community involvement and development. ${ }^{373}$ Within these seven subjects, ISO 26000:2010 includes detailed guidance on thirty-seven issues for social responsibility. ${ }^{374}$ However, although organizations cannot use ISO 26000:2010 for certification, many firms develop their sustainability reports using ISO standards nonetheless. ${ }^{375}$

\section{U.N. Guiding Principles on Business and Human Rights}

In 2011, the United Nations Human Rights Council unanimously approved of the Guiding Principles on Business and Human Rights: Implementing the United Nations "Protect, Respect and Remedy" Framework (GPs). ${ }^{376}$ The thirty-one GPs are voluntary and nonbinding, however, the OECD and others adopted recommendations adding human rights components to

\footnotetext{
369 U.N. GLOB. COMPACT, supra note 364.

370 Thought Leadership Webinar: Realizing Decent Work Through Breakthrough Innovation, U.N. GLOB. COMPACT, https: / www.youtube.com/watch?time_continue=4\&v=IA77ZfsS1lw.

${ }^{371} I d$.

372 Practical overview of the Linkages Between ISO 26000:2010, GuidanCE ON SOC. RESP. \& OECD GUIDELINES FOR MULTINATIONAL ENTERS. 8 (2011), available at http://iso26000.info/wp-content/uploads/2017/02/ISO-26000_and_OECD_ Guidelines_MNE_PPO_v1.pdf.

373 Id.

${ }^{374} I d$.

375 Id.

376 U.N. N.Y. \& GENEVA, Guiding Principles Bus. \& Hum. RTS (2011), available at https://www.ohchr.org/Documents/Publications/GuidingPrinciplesBusinessHR_EN. pdf.
} 
their own guidelines. ${ }^{377}$ The GPs require companies to perform due diligence within their supply chains and provide a remedy for impacted stakeholders. ${ }^{378}$ The GPs apply to all states and all business enterprises regardless of size, sector, location, or structure; a number of companies use the language of the GPs in their sustainability filings. ${ }^{379}$ The GPs' due diligence framework has had an impact on a number of regulations related to ESG, including U.S. and EU conflict minerals legislation, discussed in more detail below. ${ }^{380}$

The GPs also have sway over investors. For example, in addition to the ISS ESG metric mentioned in Part III, ISS has established an Ethix's Norm Based Screening platform; ${ }^{381}$ which analyzes reported business impacts related to human rights, labor rights, environmental protection, and anti-corruption as recognized under the U.N. Global Compact. ISS aims to inform investors about prospective reputational and long-term financial risks linked to investing in companies that have failed to mitigate adverse impacts.

\section{Sustainability Accounting Standards Board}

The nonprofit SASB develops standards for publicly traded companies in the United States in eleven sectors from seventy-nine industries so that they can disclose material sustainability information to

\footnotetext{
${ }^{377} I d$.

${ }^{378} I d$.

379 Although they do not bind businesses, they do bind states and states are therefore required to develop National Action Plans (NAPs) to promote responsible business conduct for those that operate in their jurisdictions. The United States' NAP, released in 2016, includes: (1) a peer review process to enhance access to remedy through the OECD complaint process; (2) stronger enforcement of existing laws related to forced labor and convict labor; (3) a best practices list related to sustainability that the government will use in the procurement process; (4) the designation of "labor compliance advisors" for federal contractors; and (5) more support for voluntary reporting on responsible business conduct by publicly recognizing the effort of compliant companies. RESP. BUS. CONDUCT: FIRST NATIONAL ACTION PLAN FOR THE UNITED STATES OF AMERICA, U.S. DEP'T ST., (Dec. 16, 2016), available at https://www.state.gov/documents/organization/ 265918.pdf.

380 The Ctr. for Hum. RTs \& Glob. Just., Panel Discussion of John Ruggie’s “Just Business: Multinational Corporations and Human Rights," N.Y. U. L., YOUTuBE (May 4, 2013), http://www.youtube.com/ watch?v=_UjdBGg0Fd0.

381 Norm-Based Screening, ISS-ETHIX (2015), https://www.issgovernance.com/file/ products/iss-ethix-norm-based-screening.pdf.
} 
investors and the public. ${ }^{382}$ SASB expects companies to use its standards when filing Forms 8-K, 10-K, 20-F, and 40-F with the Securities Exchange Commission. ${ }^{383}$ SASB examines thirty topics within five broad subject matters: (1) environment; (2) social capital; (3) human capital; (4) business model and innovation, addressing the integration of ESG factors and product innovation; and (5) leadership and governance, related to regulatory compliance, risk management, conflicts of interest, anticompetitive behavior, bribery, and other aspects that could create liability or result in the removal of the social license to operate. ${ }^{384}$

\section{B. U.S. Regulations on Corporate Social Responsibility Disclosures}

1. Dodd-Frank Conflict Minerals Act

In 2010, the United States Congress passed The Dodd-Frank Conflict Minerals Act, ${ }^{385}$ which requires U.S. issuers to disclose their use of "conflict minerals" if the minerals are necessary to the functionality or the production of a product. Under $\int 1502$, affected companies using gold, tin, tungsten, and tantalum must determine and disclose whether those materials came from the Democratic Republic of Congo or adjoining countries through a reasonable country of origin inquiry. ${ }^{386}$ The rule requires companies to report publicly through Form SD each year; providing a description of the due diligence process, the products manufactured or contracted to be manufactured that are not "DRC conflict free," the name of the independent auditor, the country from where the minerals were sourced, and the efforts used to determine which mine produced the minerals. ${ }^{387}$ In 2015 , a federal appellate court found that the disclosure requirements violated the First Amendment. ${ }^{388}$ In April 2017, the SEC's division of corporate finance indicated that it would not

\footnotetext{
382 View the Standards, SASB, https://www.sasb.org (last visited Aug. 7, 2018); About the SASB, SASB, https://www.sasb.org/about-the-sasb/ (last visited Aug. 7, 2018).

383 Id.

384 Sustainability Framework, SASB, https://www.sasb.org/standards-overview/ materiality-map/ (last visited March 17, 2019).

385 Dodd-Frank Wall Street Reform and Consumer Protection Act of 2010, Pub. L. No. 111-203, 124 Stat. 1376 (H.R. 4173 \1502(a)) [hereinafter "Dodd-Frank"]; 15 U.S.C. $\$ 78 \mathrm{~m}$.

${ }^{386} I d$.

38715 U.S.C. $\$ 78 \mathrm{~m}(\mathrm{p})(1)(\mathrm{A})(\mathrm{i})$-(ii).

388 Nat'l Ass'n of Mfrs. v. SEC, No. 13-5252 (D.C. Cir. Aug. 8, 2015).
} 
recommend enforcement against companies that fail to comply with the requirement to file a conflict minerals report although it would expect companies to still file their Form SD. ${ }^{389}$ In June 2018, the Investor Alliance for Human Rights, which consists of nearly 50 investor groups with $\$ 1.2$ trillion in assets under management, issued a statement urging companies to continue to disclose. ${ }^{390}$

Retailers or manufacturers doing business in California and have an annual worldwide gross receipts exceeding $\$ 100$ million must comply with the California Transparency in Supply Chains Act of 2010. ${ }^{391}$ This law requires that certain companies disclose the extent of their efforts, if any, to ensure that the goods they sell are not produced by slaves, coerced labor, or those who have been victims of human trafficking. ${ }^{392}$ Companies must disclose, at a minimum, what actions they are taking in the following five areas: verification of their supply chains to evaluate and address risks on human trafficking and slavery; auditing of suppliers to evaluate their compliance with company standards; requiring certification from direct suppliers that they are complying with the laws regarding slavery and human trafficking in the countries in which they do business; maintaining internal accountability standards for employees and contractors who fail to meet company standards; and providing training to employees and management with direct responsibility for supply-chain management risk mitigation regarding slavery. ${ }^{393}$ Companies that do not comply must disclose on their company's website. ${ }^{394}$ In addition, a number of watchdog groups, such as Know the Chain, ${ }^{395}$ publish information on those companies that do not comply.

389 Updated Statement on the Effect of the Court of Appeals Decision on the Conflict Minerals Rule, U.S. SEC. ExCH. COMM'N, https://www.sec.gov/news/public-statement/corpfinupdated-statement-court-decision-conflict-minerals-rule (last visited Aug. 7, 2018).

390 Investor Expectations on Conflict Mineral Reporting, INV. ALL. HuM. RTS., available at https://investorsforhumanrights.org/sites/default/files/attachments/201806/InvestorExpectationsConflictMineralReporting_5.31.18_FINAL.pdf.

391 Kamala D. Harris, AtT'y Gen. Cal. Dep’t Just., The California TRANSPARENCY IN SuPPly CHAINS ACT (2015), available at https://oag.ca.gov/ sites/all/files/agweb/pdfs/sb657/resource-guide.pdf.

${ }^{392} I d$.

${ }^{393} \mathrm{Id}$.

${ }^{394} I d$.

395 KNOwTHECHAIN, https://knowthechain.org/ (last visited Aug. 7, 2018). 


\section{Federal Acquisition Regulations}

The U.S. federal government is the largest procurer of goods and services in the world. ${ }^{396}$ In 2012, President Obama enacted Executive Order 13627 and supplemented it in 2015 with a new Order, "Ending Trafficking In Persons." 397 Those subject to the law must not deny an employee access to his or her identity or immigration documents; use misleading or fraudulent practices while recruiting; use recruiters who do not comply with local labor laws; charge employees recruitment fees; or provide or arrange substandard or unsafe housing. ${ }^{398}$ The rule also establishes additional requirements for contracts (other than commercially available contracts), including those in which any portion of a contract, for which the estimated value of the supplies acquired or the services required to be performed outside the United States, exceeds $\$ 500,000{ }^{399}$ For these contracts, contractors must develop a compliance plan applicable to the portions of a contract performed outside the United States. ${ }^{400}$ Contractors and subcontractors must also certify that they are not engaged in trafficking-related activities. ${ }^{401}$ Contractors that fail the requirements of the rule may be subject to penalties including termination of subcontracts, suspension of contract payments until the contractor take appropriate remedial action, retraction of the award fee, declining to exercise available options of the contract, termination of the contract for default, and suspension or debarment from government contracting. ${ }^{402}$ Companies working with the federal government should consider whether blockchain will aid in compliance, particularly because the government itself is currently considering its use.

396 Government Contracts, in LEgAL INFO. INST., CORnELL L. SCH., https://www.law. cornell.edu/wex/government_contracts (last visited Feb. 11, 2019).

397 Conny Rijken, Federal Acquisition Regulation; Ending Trafficking in Persons, FED. REG. (Jan. 29, 2015) (effective Mar. 2, 2015), https://www.federalregister.gov/documents /2015/01/29/2015-01524/federal-acquisition-regulation-ending-trafficking-in-persons.

${ }^{398} I d$.

${ }^{399} \mathrm{Id}$.

${ }^{400} \mathrm{Id}$.

${ }^{401}$ Id.

${ }_{402}$ Id. 


\section{International Regulations on Corporate Social Responsibility Disclosures}

\section{EU Non-Financial Disclosure Laws}

In 2014, the European Union passed a non-financial disclosure law otherwise known as Directive 2014/95/EU. ${ }^{403}$ Approximately 6,000 companies must include nonfinancial statements with their annual reports, and the Directive requires large companies to report on the policies that they have implemented. ${ }^{404}$ Additionally, the outcome of due diligence related to environmental protection, social responsibility and treatment of employees, human rights, bribery/anticorruption, and diversity on company boards must be reported. ${ }^{405}$ Companies that fail to provide a disclosure must explain why they have not done so. ${ }^{406}$ The Directive applies to member states; however, each member state can define its own requirements, meaning that fines can range from thousands to millions of dollars and may apply to individuals or companies. ${ }^{407}$ Thus, companies operating in more than one jurisdiction must keep abreast of the varying requirements. Most countries require an independent audit firm to verify the existence of a non-financial report. ${ }^{408}$ Companies may either issue a separate sustainability report, reference them in management reports or in annual reports, and may produce statements based on the guidance from

403 Non-financial reporting, EUR. COMM'N, https://ec.europa.eu/info/business-economyeuro/company-reporting-and-auditing/company-reporting/non-financial-reporting_en (last visited Aug. 9, 2018).

404 Id.

405 Id.

406 Id.

407 CSR EuR. \& GRI, Member State Implementation OF Directive 2014/95/EU (2017), available at https://www.globalreporting.org/resourcelibrary/NFRpublication $\%$ 20online_version.pdf.

408 Non-financial reporting, supra note 403. 
the U.N. Global Compact, the OECD Guidelines for Multinational Enterprises, or ISO 26000:2010. ${ }^{409}$

\section{UK Modern Slavery Act of 2015}

The UK Modern Slavery Act of $2015^{410}$ requires certain organizations to prepare and publish an annual slavery and human rights statement. These firms must disclose the steps they are taking to address modern slavery in their supply chains, and if they are not taking any action, they must disclose that fact. ${ }^{411}$ There is no private right of action under the UK Act; however, the Secretary of State may apply to the UK's High Court for an injunction against an organization that failed to comply with the requirements, and failure to comply with the injunction may lead to an unlimited fine. ${ }^{42}$ The UK Act applies regardless of the company's geographic location; therefore, overseas businesses that provide goods or services within the UK must also comply. ${ }^{413}$

\section{France's Duty of Vigilance Law}

In 2017, France enacted its own duty of care law, ${ }^{414}$ which covers a much broader swath of issues than the UK Act because it includes both human rights and environmental concerns. The law requires large French companies to establish and implement vigilance plans. ${ }^{415}$ These plans must explain the measures to both identify and prevent human rights and

${ }^{409} I d$.

410 Modern Slavery Act 2015, Legislation.gov.uk, http://www.legislation.gov.uk/ ukpga/2015/30/contents/enacted (last visited Aug 10, 2018).

${ }^{411} I d$.

${ }^{412} I d$.

$413 \mathrm{Id}$.

414 See The French Duty of Vigilance Law - Frequently Asked Questions, Eur. COAL. CORP. JustiCE, http://corporatejustice.org/documents/publications/french-corporate-dutyof-vigilance-law-faq.pdf (last visited July 18, 2019); Pierre Lequiller, Rapport dinformation déposé par la délégation de LAssemblée nationale pour l'Union européenne sur les comptes rendus des missions des missi dominici sur le suivi de la Conférence intergouvernementale (2007), availiable at http://www.assemblee-nationale.fr/14/pdf/ta/ta0924.pdf; Texte adopt n 924 Proposition de loi, adopte dfinitivement, par l'Assemble nationale, dans les conditions prvues l'article 45, alina 4, de la Constitution, relative au devoir de vigilance des socits mres et des entreprises donneuses d'ordre, Assemble nationale $\sim$ Les dputs, le vote de la loi, le Parlement franais (2017), http://www.assemblee-nationale.fr/14/ta/ta0924.asp (Aug 10, 2018).

${ }^{415} I d$. 
environmental risks resulting from their activities as well as the activities of the companies that they control and their subcontractors. ${ }^{416}$ The French law only applies to French companies with over 5,000 employees in France or with 10,000 worldwide, including through subsidiaries. ${ }^{417}$ Unlike the UK Act, private citizens have standing to seek an injunction to compel the publication of a report. ${ }^{418}$ Noncompliant companies are also subject to injunctive fines payable on a daily or per-event basis until the company complies. ${ }^{419}$ Companies also face civil liability. ${ }^{420}$

\section{Commonwealth Modern Slavery Act}

In November 2018, the Australian government passed its own slavery legislation. ${ }^{421}$ This mandatory reporting law focuses on survivors of slavery and will require Australia's largest businesses (and those that operate in Australia) with revenue of over $\$ 100$ million to publish an annual statement of the steps that they are taking to address modern slavery in their supply chains. ${ }^{422}$ Specifically, companies must disclose information about their structure; potential risks of modern slavery in their supply chains; the actions they have taken to assess and address these risks; and assessment mechanisms to measure effectiveness and remedial actions. ${ }^{423}$ The government estimates that the law will impact 3,000

\footnotetext{
$416 I d$.

${ }^{417} I d$.

418 Id.

419 Stéphane Brabant \& Elsa Savourey, France's Corporate Duty of Vigilance Law: A Closer Look at the Penalties Faced by Companies, REVUE INTERNATIONALE DE LA COMPLIANCE ET DE L'ÉTHIQUE DES AFFAIRES (2017), REVUE INTERNATIONALE DE LA COMPLIANCE ET DE L'ÉTHIQUE DES AFFAIRES, available at https://www.business-humanrights.org/sites/default/files/ documents/French\%20Corporate\%20Duty\%20of\%20Vigilance\%20Law\%20-\%20

Penalties \%20-\%20Int\%25271\%20Rev.Compl_.\%20\%26\%20Bus.\%20Ethics_.pdf.

${ }^{420} I d$.

421 Modern Slavery Bill 2018, Parliament of Australia, https://www.aph.gov. au/Parliamentary_Business/Bills_Legislation/Bills_Search_Results/Result?bId=r6148.

422 Abigail McGregor \& JP Wood, Modern Slavery Act: What Businesses in Australia Need to Know, NORTON ROSE FUlBright, (Dec. 4, 2018), http://www.nortonrosefulbright.com /knowledge/publications/155473/modern-slavery-act-what-businesses-in-australianeed-to-know.

${ }^{423}$ Modern Slavery in Supply Chains Reporting Requirement, Public Consultation Paper and Regulation Impact Statement (2017), COMMONWEALTH OF AusTL., available at https://www.homeaffairs.gov.au/how-to-engage-us-subsite/files/modern-slavery-
} 
companies and has announced that it will post reports in a central, publicly available repository and establish a business engagement unit to assist organizations with compliance. ${ }^{424}$ Like the UK Modern Slavery Act, the proposed act has no listed financial penalties.

\section{EU Conflict Minerals Rule}

On January 1, 2021, a new law will apply across the European Union regarding disclosure on conflict minerals ${ }^{425}$ - tin, tungsten, tantalum, and gold-and covers third-party audits for refiners and smelters and information on due diligence measures by downstream companies. The law applies beyond the Democratic Republic of Congo and defines conflict areas as: those in a state of armed conflict or fragile post-conflict area, areas with weak or nonexistent governance and security such as failed states, and any state with a widespread or systematic violation of international law including human rights abuses. ${ }^{426}$

\section{Difficulties with Disclosure and How Blockechain Could Help}

The United Nations, OECD, and GRI are already exploring blockchain for a variety of use cases, but it perhaps has the most potential in aiding companies with disclosure. Many of these disclosure rules were enacted to provide information to consumers and investors so that they can make educated decisions about the companies with which they do

reporting/modern-slavery-supply-chains-reporting-requirement-public-consultationpaper.pdf.

${ }^{424} I d$.

42560 J. E.U. 130, (May 19, 2017), https://eur-lex.europa.eu/legalcontent/EN/ TXT/HTML/?uri=OJ:L:2017:130:FULL\&from=EN. devoir de vigilance des socits mres et des entreprises donneuses d'ordre, Assemble nationale $\sim$ Les dputs, le vote de la loi, le Parlement franais(2017), http://www.assemblee-nationale.fr/14/ta/ta0924.asp (Aug. 10, 2018).

425 Brabant \& Savourey, supra note 419.

425 Modern Slavery Bill 2018, supra note 421.

425 McGregor \& Wood, supra note 422.

425 Modern Slavery in Supply Chains Reporting Requirement, supra note 423.

42560 J. E.U. 130, (May 19, 2017), https://eur-lex.europa.eu/legalcontent/EN/TXT/ HTML/?uri=OJ:L:2017:130:FULL\&from=EN.

426 The Regulation Explained, Eur. COMM’N, http://ec.europa.eu/trade/policy/in-focus/ conflict-minerals-regulation/regulation-explained/ (last visited Aug. 20, 2018). 
business; but how can stakeholders trust the data produced? Indeed, both state and nonstate actors seek the information.

Notwithstanding the disclosure requirements, most companies provide little to no meaningful disclosure in part because of the cost of complying with discordant laws, many of which have no financial penalties. Although consumers may not know the difference, other stakeholders have taken notice. NGO Know the Chain, which benchmarks forced labor issues for investors and consumers, reviewed more than 100 companies in the information and communications technology. ${ }^{427}$ They found that of the 102 companies analyzed, only 14 met the minimum compliance requirements, three years after the passage of the UK Modern Slavery Act. ${ }^{428}$ In examining compliance with the Dodd-Frank Conflict Mineral rule, the U.S. General Accounting Office found that:

[a]fter conducting due diligence to determine the source and chain of custody of any conflict minerals used, an estimated 37 percent of these companies reported in 2017 that they were able to determine that their conflict minerals came from covered countries or from scrap or recycled sources, compared with 39 and 23 percent in 2016 and 2015 , respectively. ${ }^{429}$

Failure to provide adequate or complete data frustrates the intent of these disclosure rules. Because blockchain has already shown utility in supply chain management and due diligence, it provides an obvious solution to facilitate disclosure with interconnected regimes that unfortunately do not always harmonize requirements. The two areas where blockchain may be most useful are human trafficking/forced labor and provenance of minerals.

As discussed in Part II, a number of entities are experimenting with blockchain for identity management; these projects can help comply with both human trafficking and forced labor laws. Moldova, for example,

427 What Progress Have Companies Made Under the UK Modern Slavery Act, KNOwTHECHAIN (Mar. 25, 2018), https://knowthechain.org/what-progress-have-companies-made-under -the-uk-modern-slavery-act.

${ }^{428} I d$.

${ }^{429}$ Conflict Minerals, U.S. Gov'T ACCOUnTABILITY OFF. (June 2018), https://www. gao.gov/assets/700/692851.pdf. 
has the highest rate of human trafficking in Europe. ${ }^{430}$ It has partnered with ConSenSys to use digital identification technology to combat child trafficking. ${ }^{431}$ London-based NGO Provenance is using blockchain and RFID technology to combat forced labor in the seafood industry promising to trace certain fish from "catch to consumer."432 The World Wildlife Fund has a program called "bait to plate" that uses RFID, QR codes, and blockchain to address human slavery and unsustainable practices on tuna boats. ${ }^{433}$ This is similar to the kind of system that Walmart will use with its vegetable suppliers. ${ }^{434}$ Companies wishing to prove that they have complied with laws banning recruitment fees and requiring fair payment of wages could use the blockchain to post contracts and proof of payments. ${ }^{435}$ This proof would be visible at all stages of the supply chain, depending on permissions and the appetite for small businesses and governments to participate. ${ }^{436}$ Finally, although the entities involved have revealed few details, Coca Cola and the U.S. State Department have announced a pilot program to use blockchain to create a secure registry for workers and their contracts. ${ }^{437}$

One of the most promising examples for blockchain and mineral sourcing relates to a joint project with Hermes EOS and the law firm DLA Piper. These two have been working with responsible sourcing solutions providers RCS Global and Everledger to understand how the technology can improve transparency and support risk management. ${ }^{438}$ The group

430 Jill Robinson, Public Perceptions of Human Trafficking in Moldova, 20 Psychosocial INTERVENTION 269, 270 (2011).

${ }^{431}$ Umberto Bacchi, Scan on Exit: Can Blockchain Save Maldova's Children From Traffickers?, REUTERS (June 18, 2018).

432 Alex Capri, How Blockchain Could Help End Modern Day Slavery in Asia's Exploitative Seafood Industry, FORBES (Feb. 14, 2018).

${ }^{433}$ Candice Visser and Quentin Hanich, From Bait to Plate, CoRP. KNIGHTS (Feb. 8, 2018).

434 Steve Banker, 2019 Is the Year for Blockchain Traceability, But Will It Have Legs, FORBES, https://www.forbes.com/sites/stevebanker/2019/02/02/2019-is-the-year-for-

blockchain-for-traceability-but-will-it-have-legs/\#db630333dcc4 (last visited July 18, 2019).

${ }^{435} I d$.

436 Capri, supra note 432.

${ }^{437}$ Gertrude Chavez-Dreyfuss, Coca-Cola, U.S. State Dept. to use Blockchain to Combat Forced Labor, FORBES (Mar. 16, 2018).

438 As described in a November 2018 white paper, 
showcased blockchain at the U.N. Forum on Business and Human Rights in November 2018. Through its Better Sourcing and Better Cobalt programs, RCS Global has developed a mine to market traceability solution in the Democratic Republic of Congo that could also help companies comply with Dodd-Frank and the EU's upcoming rules. ${ }^{439}$ The company's solution provides data that complies with the OECD Due Diligence Guidance for Responsible Mineral Supply Initiative Chains, the Responsible Minerals Initiative, Responsible Minerals Assurance Process (used by over 350 companies and auditors), ${ }^{440}$ and CRAFT Code of the Alliance for Responsible Mining. ${ }^{441}$ Meanwhile, Everledger has used blockchain technology to track the provenance of diamonds from origin to consumer with real time data capture. ${ }^{442}$ Diamond company DeBeers has also developed a solution called Tracer using the Ethereum

\begin{abstract}
DLA Piper is a global law firm with lawyers located in more than 40 countries throughout the Americas, Europe, the Middle East, Africa and Asia Pacific.... Everledger uses blockchain to provide immutable evidence of a product's provenance, location, propriety and forensic record. With blockchain-enabled CoC, logistics services, and material analytics Everledger can provide users with visibility throughout distributed supply chains. Hermes Investment Management is an asset manager with . . f 35.3 billion in assets under management [which] focus[es] on holistic returns [that] consider the impact our decisions have on society, the environment and the wider world. ... RCS Global Group is a world leader in data-driven responsible sourcing of natural resources with a full-time presence in Africa, China, the EU and the US. Working at each stage of the supply chain, RCS Global Group delivers audit, advisory, data, and technology solutions to enable clients to improve, measure and demonstrate good practice and impact.
\end{abstract}

Supply Chain Human Rights Risk. Management: Blockchain and Emerging Technology, DLA PIPER, Everledger, Hermes EOS, RCS GlOB., (Nov. 2018), at 2.

439 Blockchain \& Traceability, RCS GLOB., https://www.rcsglobal.com/blockchaintraceability/.

${ }^{440}$ FAQ, Resp. Minerals Initiative, http://www.responsibl emineralsinitiative.org/ about/faq/.

${ }^{441}$ CRAFT Code, ALl. ResP. Mining (July 31, 2018), http:/ /www.responsiblemines.org/ en/our-work/standards-and-certification/craft.

442 EverLedGer LtD., https://diamonds.everledger.io/; FAQ, EvERLEDGER LTD., https://diamonds.everledger.io/faq. 
Blockchain. ${ }^{443}$ DeBeers hopes to have all players from miners to retailers on the platform and will also add in a KYC component.

DLA Piper expresses optimism about blockchain's potential for provenance but poses the following questions that all companies should consider when looking to blockchain as a possible solution. ${ }^{444}$ First, do businesses see a need for a bottom up approach to supply chain risk management? ${ }^{445}$ Second, will this technology be an additional burden on small and medium sized enterprises, and should there be incentives to share costs? ${ }^{346}$ Third, will the entire market engage in the process, and how long will that take? ${ }^{477}$ Fourth, is it realistic to expect whole market engagement/change, and how long might that take? ${ }^{448}$ Fifth, will consumers or the market pay for a premium ethically-sourced minerals market backed by blockchain one day? ${ }^{449}$ Sixth, how can blockchain assist in investigations and audits to ascertain risks in the supply chain? ${ }^{450}$ Seventh, how does the technology fit into the UNGP framework of human rights due diligence? ${ }^{451}$ Finally, how can blockchain help investors measure the impact of investments related to the SDGs? ${ }^{452}$

Firms that wish to use blockchain to assist in disclosures and supply chain management should answer these questions and work with cross-industry groups. In Part V, we will reiterate the broader concerns that boards, regulators, and investors should consider prior to embracing blockchain.

${ }^{443}$ Manoj Sharma, De Beers to Launch First Diamond Blockchain; Here's How it Will Work, Bus. TODAY (Sept. 14, 2018), https://www.businesstoday.in/current/corporate/debeers-blockchain-based-tracr-to-integrate-all-diamond-businesses-on-oneplatform/story/280941.html.

444 Supply Chain Human Rights Risk Management: Blockchain and Emerging Technology, supra note 437 at 23 .

${ }^{445} I d$

${ }^{446} I d$.

${ }^{447} I d$.

${ }^{448} I d$.

${ }^{449} \mathrm{Id}$.

${ }^{450} \mathrm{Id}$.

${ }^{451} I d$.

${ }_{452}$ Id. 


\section{CONCLUSION}

As discussed above, blockchain will revolutionize banking, healthcare, politics, real estate, supply chain management, cybersecurity, infrastructure security, corporate governance, and the legal market. ${ }^{453}$ Although we did not discuss it in this Article, entrepreneurs are also looking to blockchain for education credentialing, ride sharing, car leasing, music and entertainment, intellectual property, wills and estates, cloud computing, law enforcement, and a host of use cases that require thirdparty intermediaries or trust to function. ${ }^{454}$

The world's governments and central banks are innovating as well. According to the OECD, there are over 200 public sector blockchain initiatives in 45 countries for use cases as varied as identity management, land title registry, supply chain management and inventory, benefits and entitlements, contract and vendor management, voting, and strengthening and streamlining interagency processes. ${ }^{455}$

The potential cost savings and increased security make blockchain an obvious choice for many companies, but it may not make sense for all. Many companies may be deterred by expense and time required to establish a blockchain and to convince or require partners to participate. This is a legitimate concern. If a company needs no more than a simple ledger or database, blockchain may not make sense and other options may suffice. IOTA, for example, is an open source platform which uses a "secure, scalable and feeless transaction settlement layer." to address some of blockchain's growing pains related to high transaction costs and sluggish processing times on permissionless chains. ${ }^{457}$ The Hedera platform is a public distributed ledger that promises to provide the same decentralized processes and level of security without using the computing power of traditional blockchains. ${ }^{458}$

\footnotetext{
453 Bernard Marr, Here are 10 Industries Blockchain is Likely to Dismpt, FORBES (July 16, 2018).

454 Banking is Only the Beginning: 50 Big Industries Blockchain Could Transform, CBINSIGHTS (Dec. 19, 2018).

${ }^{455}$ Jamie Berryhill et al., Blockchains Unchained: Blockchain Technology and Its Use in the Public Sector, OECD Working PaPers on Pub. Governance No. 28 (June 2018).

456 What is IOTA?, IOTA, https://www.iota.org/get-started/what-is-iota.

${ }^{457} I d$.

458 Hedra Hashgraph Platform, HeDRA HASHGRAPH, https://www.hedera.com/platform.
} 
This Article, however, has focused on permissioned blockchains and recommends that any company that manages, is part of a supply chain, or contracts with a government entity consider blockchain to avoid risking obsolescence or government regulation. Companies will not act without incentives, although we argue that the business case for certain businesses and certain industries is compelling enough.

Governments, institutional investors, and stock exchanges can and should provide incentives for investment or at least exploration into blockchain. For example, states could exempt companies that must comply with numerous disclosure regimes from reporting on an annual basis in exchange for access to a permissioned blockchain. This way regulators, auditors, and other relevant stakeholders could have real time access to data. Likewise, institutional investors who need data on a timely basis to make decisions about investment or divestment should not have to wait until quarterly reports or earnings calls to learn about data that may be salient or material. These investors, even those without BlackRock's clout, can still influence a board of directors to explore technological advances, particularly if it could make governance more transparent. Rating agencies, which assess the creditworthiness of companies, also play a role in helping investors and financial institutions understand a company's risk profile. ${ }^{459}$ They would likely welcome the opportunity to assess the data without the need to consult with the company. Stock exchanges are using blockchain already. Although they could not require blockchain as a listing requirement, they could lower annual fees or provide some other carrot for companies using blockchain, when appropriate.

Even if governments, investors, rating agencies, or stock exchanges do not push companies to explore blockchain, the marketplace will likely do so. The ten largest companies in the world and fifty of the largest firms in the Forbes 2000 are looking at blockchain, ${ }^{460}$ which means that those who do business with them up and down the supply chain may have no choice but to participate. Furthermore, consumers, investors, NGOs, and regulators demand transparency, speed, security, and streamlined processes. Blockchain is not a cure all, but it is a very good start.

${ }^{459}$ Reyes Pariente, What are Rating Agencies, BBVA (May 4, 2017), https://www.bbva.com/en/what-are-rating-agencies.

${ }^{460}$ Michael del Castillo, Big Blockchain: The 50 Largest Public Companies Exploring Blockchain, FORBES (July 3, 2018). 